NBER WORKING PAPER SERIES

\title{
A LOBBYING APPROACH TO EVALUATING THE SARBANES-OXLEY ACT OF 2002
}

\author{
Yael V. Hochberg \\ Paola Sapienza \\ Annette Vissing-Jorgensen \\ Working Paper 12952 \\ http://www.nber.org/papers/w12952
}

\author{
NATIONAL BUREAU OF ECONOMIC RESEARCH \\ 1050 Massachusetts Avenue \\ Cambridge, MA 02138 \\ March 2007
}

We thank John de Figueiredo, Wei Jiang, Holger Mueller, Morten Sorensen, Cong Wang, Luigi Zingales and seminar participants at the European Central Bank, InterDisciplinary Center Hertzlia, Iowa State University, NBER Law and Economics Summer Meeting, New York University, Northwestern University, Norwegian School of Economics and Business, Securities and Exchange Commission, UNC - Duke Corporate Finance Conference, University of Copenhagen, University of Illinois Urbana-Champaign, University of Oregon, and Yale University for helpful comments and suggestions. We are grateful to Catherine Leblond and Che Banjoko for outstanding research assistance, to Cindy Alexander for assistance with SEC requests, to Kin Lo for provision of prior lobbying data, and to Yaniv Grinstein and Vidhi Chhaochharia for provision of governance data. The views expressed herein are those of the author(s) and do not necessarily reflect the views of the National Bureau of Economic Research.

(C) 2007 by Yael V. Hochberg, Paola Sapienza, and Annette Vissing-Jorgensen. All rights reserved. Short sections of text, not to exceed two paragraphs, may be quoted without explicit permission provided that full credit, including $\odot$ notice, is given to the source. 
A Lobbying Approach to Evaluating the Sarbanes-Oxley Act of 2002

Yael V. Hochberg, Paola Sapienza, and Annette Vissing-Jorgensen

NBER Working Paper No. 12952

March 2007

JEL No. G3,G34,K22

\begin{abstract}
$\underline{\text { ABSTRACT }}$
We evaluate the net benefits of the Sarbanes-Oxley Act (SOX) for shareholders by studying the lobbying behavior of investors and corporate insiders to affect the final implemented rules under the Act. Investors lobbied overwhelmingly in favor of strict implementation of SOX, while corporate insiders and business groups lobbied against strict implementation. We identify the firms most affected by the law as those whose insiders lobbied against strict implementation, and compare their returns to the returns of less affected firms. Cumulative returns during the four and a half months leading up to passage of SOX were approximately 10 percent higher for corporations whose insiders lobbied against one or more of the SOX disclosure-related provisions than for similar non-lobbying firms. Analysis of returns in the post-passage implementation period indicates that investors' positive expectations with regards to the effects of the law were warranted for the enhanced disclosure provisions of SOX.

Yael V. Hochberg

Finance Department

Kellogg School of Management

Northwestern University

2001 Sheridan Road

Evanston, IL 60208-2001

y-hochberg@ kellogg.northwestern.edu

Paola Sapienza

Finance Department

Kellogg School of Management

Northwestern University

2001 Sheridan Road

Evanston, IL 60208-2001

and NBER

paola-sapienza@northwestern.edu

Annette Vissing-Jorgensen

Finance Department

Kellogg School of Management

Northwestern University

2001 Sheridan Road

Evanston, IL 60208-2001

and NBER

a-vissing@northwestern.edu
\end{abstract}


Following the Enron/Arthur Andersen scandal in late 2001, the U.S. Congress came under increasing pressure to pass legislation that would make it more difficult and costly for corporate insiders to misrepresent company performance and divert resources for personal gain. Bills were introduced in the House by Representative Michael Oxley on February 13, 2002, and in the Senate by Senator Paul Sarbanes on May 8, 2002. The final bill, the Sarbanes-Oxley Act of 2002, was passed in the House and Senate on July 25, 2002.

There are two main competing views about the likely impact of the Sarbanes-Oxley Act (SOX) on shareholders. Proponents of the Act argue that it will lead to improved disclosure and corporate governance, thereby reducing misconduct of insiders, and that these benefits will outweigh the costs of compliance. Opponents argue either that SOX will be ineffective in preventing corporate wrongdoing and/or that any benefits of SOX will not be large enough to outweigh the compliance costs associated with it.

The central challenge to distinguishing between the two main views regarding the effect of SOX is the lack of a control group of publicly traded firms unaffected by the legislation. In this paper, we employ two approaches in an attempt to circumvent the lack of a control group of comparable firms unaffected by SOX. Our methodology follows from the procedural process used in the implementation of the SOX legislation.

Following the passage of SOX in 2002, Congress delegated the drafting and implementation of the principles outlined by SOX to the Securities and Exchange Commission (SEC). The various sections of SOX were divided into separate rules by the SEC, which then solicited public comments regarding its proposing rule releases, prior to drafting the final adopting releases. Letters to the SEC commenting on the proposed rule releases were made publicly available on the SEC web site or through its public reference office.

Following the main compliance-related titles of SOX, we classify the rules on which the SEC solicited comments into groups, focusing on three major sets of rules: provisions related to enhanced financial disclosure (including the much discussed Section 404 assessment of internal controls), provisions related to corporate responsibility, and provisions related to auditor independence. Our first approach to evaluating the effect of SOX on shareholder value is to classify the nature of comment letters submitted to the SEC by individual investors and investor groups. We document that based on their letters to the SEC, individual investors were overwhelmingly in favor of strict implementation of SOX, across all three categories of proposed rules. Importantly, lobbying by 
investor groups such as pension funds and labor unions, who presumably are more sophisticated than individual shareholders, was equally supportive. These findings allow us to speak to the perceived value of SOX for shareholders. To the extent that investors were sufficiently informed and sufficiently sophisticated to evaluate the costs and benefits of SOX, these findings suggest that SOX was perceived to be beneficial to individual investors and investor groups. This result stands in stark contradiction to the conclusions of studies such as Zhang (2005), who argue that shareholder reactions to SOX were unfavorable based on the price movement of the market as a whole.

To provide additional evidence on the value of SOX, our second approach utilizes the comment letters sent to the SEC by and on behalf of corporate insiders. Our reading of these letters reveals that an overwhelming majority of insiders in lobbying companies opposed strict implementation of SOX, and argued strongly for delays, exemptions and loopholes in its implementation. While lobbying by investors in favor of SOX is useful for distinguishing between the improved disclosure and corporate governance view and the costly compliance view of SOX, lobbying by insiders against strict implementation is not informative for this purpose in and of itself. Corporate insiders may lobby against strict implementation of SOX both if SOX was expected to succeed in improving disclosure and governance or if the dominant effect of SOX was expected to be its high compliance costs. $^{1}$

Lobbying by corporate insiders against strict implementation of SOX, however, can be used as a proxy to identify companies more likely to be affected by the legislation (positively or negatively), and thus allows us to circumvent the lack of a control group of firms unaffected by the Act. Under the improved disclosure and governance view, these more affected firms will be those for whom the governance gain will be greatest. If SOX provides a net benefit in the form of improved disclosure and corporate governance for shareholders, companies whose insiders lobbied against strict implementation of SOX should have higher cumulative returns than otherwise similar nonlobbying companies in the period leading up to the passage of SOX, as the market adjusts its expectations of future cash flows for these companies relative to their matched, less-affected peers. Conversely, under the compliance cost view, where SOX is detrimental to shareholders because it imposes costs that outweigh any associated governance gains, the more affected companies will be those for whom the net costs are highest, and thus we would expect lobbyers to experience lower

\footnotetext{
${ }^{1}$ Under the improved disclosure and governance view, insiders lobby against strict implementation due to SOX's effect of reducing insiders' ability to divert resources to themselves. Under the compliance cost view, insiders may lobby against SOX either because they choose to lobby in the interest of company shareholders, or because they anticipate a possible reduction in diversion of resources.
} 
cumulative returns than non-lobbyers.

One aspect of our research design, important for interpreting our findings, is that lobbying of the SEC with regards to implementation of SOX primarily occurred after the passage of the Act itself. For our identification strategy to be powerful, it must be the case that the market could predict which firms would be most affected (and hence, which insiders would lobby against strict implementation of SOX) based on ex-ante observable characteristics of firms. To validate our empirical strategy, we provide direct evidence that lobbying was to some extent predictable based on variables publicly observable at the start of our sample. Furthermore, an event study of abnormal returns observed around the date of submission of a comment letter by a given company indicates that there was no discernable market reaction to the submission of the letter, suggesting that market participants were not surprised to see which firms lobbied.

Our portfolio analysis of returns reveals that during the period from February to July of 2002 leading up to passage of SOX, cumulative returns were approximately 10 percentage points higher for corporations whose insiders lobbied against one or more of the SOX 'Enhanced Disclosure' provisions than for non-lobbying firms with similar size, book-to-market and industry characteristics. Similarly, we find some evidence of higher cumulative returns for corporations whose insiders lobbied against one or more of the SOX 'Corporate Responsibility' provisions and for corporations whose insiders lobbied against one or more of the SOX 'Auditor Independence' provisions than for comparable non-lobbying firms. Many firms who lobbied against strict implementation of the 'Corporate Responsibility' or 'Auditor Independence' provisions, however, also lobbied against strict implementation of one or more of the 'Enhanced Disclosure' provisions. We therefore proceed to estimate the separate abnormal returns associated with each of the three categories by running firm-level regressions. The results from our firm-level models imply a total abnormal excess return of approximately 10 percent during the period leading up to the passage of SOX for firms whose insiders lobbied against the 'Enhanced Disclosure' provisions, but a total abnormal excess return of only 3 percent and 1 percent for firms lobbying against 'Corporate Responsibility' or 'Auditor Independence' provisions, respectively. These relative returns suggest that while investors did not disapprove of the 'Corporate Responsibility' or 'Auditor Independence' provisions, the market expected SOX to mainly benefit the firms most affected by provisions related to 'Enhanced Disclosure,' rather than those affected primarily by 'Corporate Responsibility' provisions or 'Auditor Independence' provisions. 
In the second part of our analysis, we focus on the returns of lobbying and non-lobbying firms during the period after the passage of SOX. If investors' positive expectations regarding the overall effects of SOX were warranted, one would not expect any differences between the returns of lobbying and non-lobbying firms in the post-passage period. If, on the other hand, shareholders gradually became aware that the measures introduced by SOX did not in fact result in higher earnings, due, for example, either to a watering down of the rules during implementation or to higher than expected compliance costs (for more affected firms in particular), then one should observe abnormal negative returns for lobbying firms relative to non-lobbyers in the period following SOX passage and until investor expectations settle at a new, less optimistic level. Our analysis of returns in the post-passage period indicates that the returns for firms who lobbied against an 'Enhanced Disclosure' rule were similar to the returns for their non-lobbying comparison group of firms, and thus that the increase in relative stock price experienced by lobbying firms did not tend to reverse during the post-passage period.

To further validate our reseach design, in the final part of our analysis, we repeat the study of returns described above, replacing the lobbying firms with those firms who, based on ex-ante characteristics, our probit model would predict would lobby. We find roughly similar results when employing predicted lobbyers rather than actual lobbyers as the proxy for more affected firms.

In sum, our study documents, first, that investors expected SOX to more closely align interests of insiders and shareholders; second, that (relative) returns during the period leading up to SOX passage are consistent with the views of investors; and third, that investors' positive expectations may have been warranted, based on returns in the post-SOX period. Consistent with the arguments presented by Coates (2006), our results indicate that in the eyes of public company shareholders, the most important and effective provisions in SOX were the 'Enhanced Disclosure' provisions, rather than the provisions related to 'Corporate Responsibility' and 'Auditor Independence'.

An obvious shortcoming of a research design which compares more affected firms to less affected firms, without having a comparable group of firms unaffected by the legislation studied, is that it does not speak directly to the overall effect of SOX on the public equity market. We can say that considering the full period from when serious discussions about the legislation first started in week 7 of 2002 and until the end of 2004 (well into the implementation phase of SOX), the stocks of more affected firms (as proxied for by lobbying firms) outperformed those of less affected firms (proxied for by non-lobbying firms). Based on our returns analysis alone, we cannot unambiguously say 
that the net benefit of SOX for either group is positive. However, we employ estimates of SOX compliance costs and argue that the benefit to shareholders in the more affected (lobbying) firms is likely to be positive. Furthermore, with the addition of two conservative assumptions, we argue that the new benefit to shareholders in general is likely to be positive.

A second important caveat to our analysis is that we are not able to speak to the welfare effects of SOX, but rather only to the law's effects on shareholders of publicly listed companies at the start of our sample. For example, our analysis cannot measure the overall welfare effect of changes in the propensity to list or remain listed on U.S. markets due to SOX-related costs (Zingales (2006)). In addition, we cannot rule out that insiders lost an amount equal to or greater than what outside investors gained. Finally, we note that while our analysis suggests that shareholders expected SOX to be value-increasing on average for publicly traded firms, the lobbying firms in our sample are predominantly large, established organizations, and thus our returns analysis does not provide specific conclusions as to the effect of SOX on smaller firms.

Our study is related to an emerging literature attempting to evaluate the effects of SOX. An insightful review of this literature, which has not produced a general consensus on the effects or value of the Act, is presented in Coates (2006). Zhang (2005) examines the reaction of the overall U.S. stock market to legislative events leading to the passage of the Act. While Zhang (2005) finds significantly negative returns around legislative events leading to the passage of SOX, these returns might be due to other, confounding events unrelated to SOX. Rezaee and Jain (2003) also study the aggregate market reaction to SOX, reaching the opposite conclusion of Zhang (2005).

As in our paper, other studies seek to circumvent the lack of a control group of unaffected firms by use of alternative approaches or outcome variables. Cohen, Dey and Lys (2005) evaluate the impact of SOX by examining changes in earnings management behavior and in the informativeness of earnings announcements of firms around the passage of the Act. They find a decline in earnings management activity following the passage of SOX. Engel, Hayes and Wang (2004) study firms' going-private decisions and find a modest increase in the number of firms going private after the passage of SOX. The paper closest to ours in approach is Chhaochharia and Grinstein (2005), who study the announcement effect of SOX on firm value. To overcome the lack of an unaffected control group, they sort firms into groups most and least compliant with certain proposed SOX provisions in the pre-SOX period. Based on a comparison of these two groups, their study finds a positive value effect associated with SOX for large firms, whereby firms that need to make the 
most changes in order to comply with the new rules outperform firms that require fewer changes over the announcement period. Conversely, they find a negative effect for small firms. While Chhaochharia and Grinstein (2005) study the perceived value of SOX for firms most affected by certain specific provisions of the Act, our lobbying approach allows us to expand on their work by examining shareholders' views regarding the full spectrum of SOX's provisions, as well as to differentiate between the various categories of these provisions. Additionally, since our analysis extends to the period after the passage of the law, we are also able to separate the perceived effects of the Act as passed in Congress from the net effects resulting from the actual implementation of those rules.

Our paper is also related to a growing literature that uses the lobbying activities of corporations to examine the impact of regulation. King and O'Keefe (1986) examine the relationship between corporate lobbying and trading activities of corporate insiders surrounding proposed accounting standards that require firms to expense oil and gas exploration expenditures associated with dry holes. A more closely related study is that of Lo (2003), who examines the economic consequences of the 1992 revision of executive compensation disclosure rules using a lobbying approach quite similar to that employed in this study. Lo (2003) finds, in support of the value of increased disclosure, that corporations whose insiders lobbied the SEC against the proposed regulation had positive excess stock returns of about $6 \%$ over the 8 -month period between the SEC's announcement that it would be pursuing reform and the adoption of the proposed regulation. In addition to addressing a different reform, a key difference between Lo (2003) and this study is that we study not only the opinions of corporations who lobby the SEC, but also the views of non-investor groups and of individual investors and investor groups.

The remainder of this paper is organized as follows. Section I presents an overview of the Sarbanes-Oxley Act, the time line of its adoption, and the role of lobbying in the design of the resulting rules. Section II details our hypotheses and research method. Section III presents and our empirical findings. Section IV discusses the interpretations and implications of our findings. Section V concludes. 


\section{The Sarbanes-Oxley Act Of 2002}

\section{A. The Legislative Time-Line}

The collapse of Enron in October 2001, followed by the subsequent exposure of a string of accounting and governance scandals at Qwest Communications, Global Crossing, Worldcom, Adelphia and Tyco in the spring of 2002, triggered a flurry of legislative proposals to reform corporate business practices and improve accounting and governance systems for publicly traded companies.

The Sarbanes-Oxley Act resulted from the combination of reform bills introduced by Senator Paul Sarbanes, Democrat of Maryland, and Representative Michael Oxley, Republican of Ohio, in the Senate and House, respectively. Representative Oxley's reform bill was first introduced in the House on February 13th, 2002. Oxley's bill was passed in committee on April 16th, 2002, and was subsequently passed in the House on April 24th, 2002. In May of 2002, the Sarbanes reform bill was circulated in the Senate Banking Committee, which passed the bill on June 18th, 2002. The full Senate began debate on Sarbanes' bill on July 8th 2002, and passed the bill with overwhelming support on July 15th, 2002. On July 19th, 2002, the House and Senate formed a conference committee and began negotiations to merge the two bills. The final legislative bill, to be known as the Sarbanes-Oxley Act of 2002, was passed in Congress on July 25th, 2002, and was signed into law by the President on July 30th of that year.

SOX directed the SEC to immediately begin rule-making activities, and the SEC commenced such action in late August 2002. SOX-directed rule making activities continued throughout 2003 and into the beginning of 2004. The major rule-making activities were completed by June 2004 .

\section{B. The Content of the Act}

The Sarbanes-Oxley Act established the Public Company Accounting Oversight Board (PCAOB) and laid out new rules for and restrictions on corporations, corporate directors and auditors. The Act is arranged into eleven titles.

The first four titles of the Act are the most relevant for issues of public company compliance. Title I of the Act establishes the PCAOB, which is charged with overseeing and registering public accounting firms and establishing standards related to auditing and internal controls. Title II of the Act covers issues related to auditor independence, and places restrictions on public accounting firms with regards to the provision of non-auditing services, as well as mandating periodic rotation

of the coordinating and reviewing auditing partners. Title III of the Act deals with corporate re- 
sponsibilities, including the independence of the auditing committee, improper influence on conduct of audits, executive certification of financial reports, penalties related to financial restatements, and rules of professional responsibility for attorneys. Title IV of the Act deals with enhanced financial disclosure, including disclosures in periodic reports, enhanced conflict of interest provisions, disclosure of transactions involving management or principal stockholders, the disclosure of the existence of an audit committee financial expert, and the much-discussed management assessment of internal controls.

The remaining titles of the Act primarily deal with issues unrelated to compliance by publicly traded firms, or set out criminal penalties and as such were (with two exceptions noted below) not subject to interpretation and implementation by the SEC. Title V of the Act deals with analyst conflicts of interest, Title VI deals with SEC resources and authority, and Title VII with studies and reports. Title VIII of the act deals with corporate and criminal fraud accountability, and Title IX with white collar crime penalty enhancements. Title $\mathrm{X}$ deals with the signing of corporate tax returns by chief executive officers, and Title XI with definitions of corporate fraud and accountability. Of these remaining titles only Title VIII, section 802, on criminal penalties for altering documents and Title IX, Section 906, on corporate responsibility for financial reports generated SEC rule-making. We group SEC rules related to Sections 802 and 906 with those related to Title III since they cover similar topics. Due to the SEC's lack of rule-making activities with regards to Title V, VI, VII, X and XI, we do not deal directly with these Titles of the Act.

We classify the rule-making activities of the SEC with regards to Titles I through IV of SOX into three broad categories. Rule-making activities related to auditor independence, Title II of SOX, are classified as 'Auditor Independence' rules. Rule-making activities related to corporate responsibilities, Title III of SOX, are classified as 'Corporate Responsibility' rules. Rule-making related to issues of enhanced financial disclosure and the PCAOB, Titles IV and I of SOX, are classified as 'Enhanced Financial Disclosure' rules. We include Title I, which establishes the PCAOB, in the 'Enhanced Disclosure' rules category due to the close overlap between the PCAOB's responsibilities and rule-making and the disclosure items mandated in Title IV. Indeed, a significant part of the PCAOB's purpose is to determine and regulate the standards for the enhanced disclosures mandated by Title IV. ${ }^{2}$

In conjunction with the federal legislation, the major stock exchanges produced their own

\footnotetext{
${ }^{2}$ All our reported results are robust if the rules relating to Title IV are analyzed separately from those relating to the PCAOB.
} 
governance-related listing requirements. In February of 2002, the SEC called on the major stock exchanges to review their governance requirements. NYSE's and NASD's boards adopted governance proposals and submitted them to the SEC for approval. The SEC solicited public comment on these proposals, and upon reviewing the comments, approved the NYSE and NASD proposals with some modifications. We include SEC rule-making related to the governance and listing standards of the NYSE and NASDAQ exchanges in the 'Corporate Responsibilities' category.

Additionally, contemporaneously with SOX rule-making, the SEC issued a number of proposed rules on disclosure-related issues which were either adopted or replaced by a SOX mandated rule. Due to the topics of these rules, they are included in the 'Enhanced Financial Disclosure' category. ${ }^{3}$ In the fall of 2003, the SEC proposed one further rule related to corporate responsibility, which was not part of SOX, and which eventually was not implemented. This rule relates to nominations of directors by security holders. We tabulate letters for this rule in Appendix A, but subsequently leave out firms that lobbied for or against this rule from our sets of lobbying and non-lobbying firms since the rule was not implemented.

\section{The Role of Lobbying in the Design of the Rules}

The Sarbanes Oxley Act is a statute, and as such, can only be changed by another Act of Congress or by a court that rules it unconstitutional. As Congress was well aware of the lengthy time-line required to perpetuate new or amended legislation, SOX mainly consisted of principles. The rules and enforcement actions by which these principles are implemented were left to be set by the SEC, which can respond rapidly to feedback and update the rules as needed (Coates (2006)).

Section 3A of the Sarbanes-Oxley Act grants authority to the Securities and Exchange Commission to "promulgate such rules and regulations, as may be necessary or appropriate in the public interest or for the protection of investors, and in furtherance of this Act." The SEC started rule-making activities in August 2002. The rule-making activities directed by SOX continued into 2003 and 2004. The SEC took public comments into consideration when drafting the final rules, and indeed, shareholders, corporations and others could and did influence how strictly SOX was implemented.

After the passage of SOX, the relevant sections of each title were broken down and drafted in a proposing release, which was then circulated by the SEC for public comment. At the end of the comment period, the SEC drafted and approved a final adopting release for each rule. In Appendix

\footnotetext{
${ }^{3}$ All our reported results are robust to exclusion of these rules.
} 
A we classify and briefly describe all of the SOX-related rules proposed by the SEC. We report the date of the proposing release, the date of the adopting release, the related SOX section, and whether the rule was adopted with or without amendments and further restrictions. ${ }^{4}$

For each of the proposed rules, the SEC solicited public comments that were to be submitted to the SEC after the proposing release date by a specific deadline prior to the adopting release date. Comment letters submitted to the SEC by electronic means are made available to the public on the SEC website. Comment letters submitted in paper form were made available through the SEC public reference section. In Section III, we describe the content of the letters submitted to the SEC in detail.

The major event window we employ to understand the perceived value of SOX is the time period leading to the approval of the Sarbanes-Oxley Act. Our event window starts on February 8, 2002, and ends on July 26, 2002. The first week of our event window leading up to SOX passage is thus the week that includes February 13, 2002, when Oxley's bill was introduced in the House and the SEC announced that it intended to propose several rules designed to improve disclosure and governance. The last week of the window includes July 25, 2002, when Congress passed the law. ${ }^{5}$ Because most of the rule making activity is concentrated after the passage of the Act (after July 25th, 2002), the event window allows us to separate the perceived effect of the law from the information potentially generated by the submission of comments to the SEC.

To understand the effects of SOX as implemented, as opposed the perceived effects of the bill as passed by Congress, we also examine the period following the passage of the Act, from July 26th, 2002, to the end of 2004. By examining returns for lobbying and non-lobbying firms in the post-passage period, we can assess the net effect of the final SOX rules, given the strictness and effectiveness of the implementation, and the costs of compliance associated with such.

\section{Hypotheses and Research Method}

There are two competing views of the likely impact of SOX. The view on which Congress based the act is that SOX would improve disclosure and governance, thereby decreasing misconduct by corporate insiders and increasing value for shareholders above and beyond the associated costs of

\footnotetext{
${ }^{4}$ Three of the proposing releases that we list as releases generated by SOX were issued before the actual passage of the law. These are cases where the content of the SEC's proposed rule subsequently was mandated by SOX and adopted as such, or where the SEC's proposed rule was augmented by a subsequent release under SOX and adopted as such.

${ }^{5}$ While the president only signed the law on July 30, 2002, presidential approval was viewed as a foregone conclusion once the Act was passed in Congress.
} 
compliance. Under this positive view of the act we would expect the following:

1. Lobbying: Shareholders should support SOX, while corporate insiders should oppose it.

2. Returns during the period leading up to passage of SOX: In the cross-section of firms, returns should be higher for more affected firms. ${ }^{6}$

The improved disclosure and governance view of the Act also predicts that, on average, across firms, returns during the period leading up to passage should be abnormally positive (relative to a set of firms with no news about disclosure and governance), and average operating performance should improve in the post-SOX period. Given the lack of a control group of (comparable US) firms not impacted by SOX, these additional predictions are impossible to test, as they cannot be distinguished from aggregate shocks unrelated to SOX.

The alternative view of SOX is that the main impact of SOX would be to impose large compliance costs on firms with a negative net effect of the act on shareholder value. This view is based on the prior that SOX would be ineffective in diminishing any misconduct, and that compliance costs would be sufficiently large to outweigh any benefits. Proponents of this view would argue that private markets already lead to the shareholder value maximizing disclosure and governance structure, and that government interference leads to sub-optimally large amounts of resources being spent on disclosure and governance issues. Under the compliance cost view, one would expect the following:

1. Lobbying: Shareholders should oppose SOX. Corporate insiders should either oppose it (if they are acting on behalf of shareholders or if SOX has some ability to reduce insider misconduct), or be indifferent to it (if SOX is ineffective in reducing insider misconduct).

2. Returns during the period leading up to passage of SOX: In the cross-section of firms, returns should be lower for more affected firms.

The compliance cost view also has predictions about the average effect of SOX across firms. Returns during the period leading up to passage should be abnormally negative (relative to a set of firms with no news about disclosure and governance), and operating performance should be worse

\footnotetext{
${ }^{6}$ As the probability of legislation went from zero to one, the price of a given company should gradually move upward from $P$ to $P+\Delta P_{\text {sox }}$ where $\Delta P_{\text {sox }}$ is the present value of the increase in dividends due to SOX. If $\frac{\Delta P_{s o x}}{P}$ differs in the cross-section, firms with large values will be observed to have abnormally good returns over this period.
} 
in the post-SOX period. Once again, given the lack of a control group of firms not impacted by SOX, these predictions are impossible to test.

From the above, it is clear that studying lobbying behavior is informative about the average effect (across companies) of SOX on shareholders. The views of shareholders are particularly informative, while lobbying by corporate insiders against SOX contains less direct evidence about SOX's average effect on shareholders, since insiders should oppose SOX under both the improved disclosure and governance view and the compliance cost view. Lobbying by insiders is however still useful for distinguishing between the two views of SOX, under the assumption that insiders are more likely to lobby in firms more affected (positively or negatively) by SOX. Under this assumption, firms can be split into groups based on whether the insiders lobbied against SOX or not, and this split can be used to test the cross-sectional predictions regarding returns during the period leading up to passage of SOX.

One aspect of our research design is important for interpreting our findings. The majority of lobbying occurs after the passage of SOX in congress on July 25th, 2002. Our approach to testing the predictions for stock returns during the period leading up to passage will therefore only be powerful if (i) shareholders were aware which types of firms were likely to lobby, and (ii) the relationship between lobbying and returns is causal.

In our analysis, we will provide three pieces of evidence to demonstrate (i) above. First, we examine the extent to which lobbying is predictable based on variables known at the start of our sample. Second, we conduct a firm level event study of returns for lobbying firms around the date of submission of a letter to the SEC. To the extent that lobbying is to some extent predictable, and the event study reveals no abnormal returns, these tests provide support for our research design and the interpretability of our findings. Third, to the extent that our analysis does reveal differences in the returns over the leadup period for lobbying and non-lobbying firms, this will provide evidence in and of itself that our assumption is reasonable.

While the reverse causality concern raised in (ii) is potentially a problem, our research design allows us to speak to this issue. Reverse causality in our setting would imply that good returns caused insiders to lobby. However, any such effect would not predict a significant differential in the excess returns of lobbying firms (over and above similar non-lobbyers) when comparing the pre- and post-passage periods. To the extent that excess returns of lobbyers differ in the pre- and post-passage period, this suggests that causality goes in the direction we assume, i.e. that being 
more affected by SOX leads to excess returns, rather than it being simply the case that better (or worse) performing firms tend to lobby, without neccesarily being more affected by the legislation. A significant differential in the pre- and post-passage excess returns of lobbyers will thus validate our research design.

It is worth noting that while this approach can be used to help resolve the causality concern in our return analysis, we cannot use a similar approach to examine changes in operating performance for lobbying and non-lobbying groups in a causal fashion: while return data is available on a weekly basis, operating performance is only available to us on an annual basis, and thus does not allows us to examine whether there is a kink in performance around the date of SOX passage. Following the presentation of our findings on lobbying and returns, we will return to the question of what we can learn from an analysis of operating performance in this setting.

A natural question that arises if indeed lobbying is predictable, is why we should choose to use lobbying as a proxy for more affected firms, rather than simply using the variables that predict lobbying. There are two central advantages to a research design that employs lobbying rather than its predictors. First, lobbying is likely a stronger proxy for being more affected than the predictors of lobbying alone. By employing the predictors instead of lobbying itself, the researcher is limited to a few observable variables that likely do not fully capture many of the aspects of a firm's structure or management that may cause it to be more affected by SOX (and which may be known to the market). We cannot as econometricians observe the state of a firm's internal controls, nor many aspects of its governance or management. Indeed, while we will demonstrate that lobbying is to some extent predictable, it is clear from our results in the following section that a substantial amount of the variation in lobbying is not driven by variables observable to us. ${ }^{7}$ Lobbying, on the other hand, is in essence revealed preference, and therefore is likely to capture many more of these aspects of the firm. Second, some characteristics will tend to predict lobbying against all the different categories of SOX-related rules. Using predictors rather than actual lobbying would therefore make it difficult to distinguish the relative benefit of the various subsections of SOX. In contrast, lobbying can be observed at the individual rule level, thus allowing the researcher to distinguish between shareholders' reactions to different aspects of SOX. Nonetheless, we will provide supplementary results analyzing the returns of firms that would be predicted to lobby based on their ex-ante observable characteristics, regardless of whether or not they actually lobby. Similar

\footnotetext{
${ }^{7}$ In contrast, it is reasonable to assume that shareholders were able to observe more information in real-time than we as econometricians can observe, and therefore that they were better able to predict lobbying than our models can.
} 
patterns in returns for these firms in the pre- and post-passage periods will lend further support to our research design.

\section{Results}

\section{A. Opinions of Letter Writers}

The opinions of commenters are tabulated in Table I. Overall, our study is based on 2689 letters. Panel A shows how the letters are distributed across various types of letter writers. Of the 2689 letters, 793 are from corporations (or more precisely, from corporate managers or directors). 253 are from non-investor groups such as the Business Roundtable and the American Society of Corporate Secretaries. 275 of the letters are from investor groups, typically pension funds (including union pension funds), and 553 are from individuals. The remaining 815 letters are from accountants (individuals and groups), lawyers (individuals and groups), academics, or others (mainly church groups and governments). Around 92 percent of the letters were submitted after July 25th, 2002, the date of the passage of the Act, with 34 percent submitted in the remainder of 2002, 48 percent submitted in 2003 and 10 percent submitted in 2004.

We classify the letters into three categories. Letters classified as "Positive" are those who favored the rule commented on, or who called for stronger measures than those stated in the SEC's proposing release. Letters classified as "Negative" are those who opposed the rule commented on, or argues for delays or exemptions in its implementation. The last category, "Neutral", is used for letters which commented on several of the sub-provisions in a particular proposing release and where the commenter was positive on some sub-provisions and negative on others. A small number of letters which were difficult to classify are also included in the neutral category.

The top panel of Table I shows for each type of commenter, and across all rules, the total number and percentage of positive letters, neutral letters, and negative letters. It is clear that individuals and investor groups were overwhelmingly in favor of the SOX provisions. 78 percent of letters from individuals and 88 percent of letters from investor groups were in favor of the rule commented on. An important feature of comment letters from individual and investor groups is that the opinions expressed are not specific to a particular firm. In other words, the letters most likely state the letter writer's view of the average effect of the particular provision across stocks, as opposed to its effect on an individual firm. Of course, it is possible that some individuals may be motivated by particularly poor disclosure/governance for a particular firm whose stock they 
own. However, since the provisions of SOX apply to all publicly traded firms, it seems fair to consider opinions expressed as views about the total set of stocks the investor/investor group holds or intends to hold in the future. Under this assumption, the positive views expressed by the vast majority of individual investors and investor groups provide support for the improved disclosure and governance view of SOX.

The remainder of Table I tabulates opinions by the rule and major rule category commented on. We first present results for the major rule category 'Enhanced Financial Disclosure and PCAOB' (SOX Title IV and I) ${ }^{8}$, then turn to the results for 'Corporate Responsibility' (SOX Title III) and last the results for 'Auditor Independence' (SOX Title II). The 'Auditor Independence' rule generated much fewer comments, the majority of which were submitted by accountants and accounting firms.

Approximately 80 percent of both individual investors and investor groups wrote in favor of the 'Enhanced Disclosure' rule they were commenting on, with similar results for individual investors and investor groups that comment on a 'Corporate Responsibility' rule. Investors thus appear to view both the disclosure and governance provisions of SOX as being value increasing, even after any compliance costs borne by shareholders. Investor groups who lobbied were overwhelmingly in favor of the 'Auditor Independence' rules, while the few individuals who commented on these rules were more divided.

The opinions of corporations and of non-investor groups contrast starkly with those of investors. Across all rules, 82 percent of letters written by corporations (corporate managers or directors) and 72 percent of letters written by non-investor groups argued against the rule they commented on. Roughly similar percentages of letters from corporations and non-investor groups express negative views about the rules in all three individual categories of SOX provisions.

Since both the improved disclosure and governance hypothesis and the compliance cost hypothesis predict that insiders should lobby against SOX, alternative theories are required to explain the 7 percent of corporations and 17 percent of non-investor groups who lobbied in favor of the rule commented on. At least one CEO of a large publicly traded firm has stated that he is in favor of SOX because compliance costs were disproportionately large for smaller firms and therefore put these at a competitive disadvantage. An alternative story for positive lobbying by a minority of corporations and non-investor groups is that these CEOs acted on behalf of shareholders and thus

\footnotetext{
${ }^{8}$ For brevity we will refer to this category as 'Enhanced Disclosure' in what follows.
} 
expressed views in line with those of the majority of individuals and investor groups. ${ }^{9}$

For data availability reasons, our subsequent analysis focuses on publicly traded corporations. A given letter may be signed by managers or directors of multiple companies. 80 percent of the 793 letters from corporations are signed by at least one manager/director from a publicly traded company. Letters that represent insiders of publicly traded firms are even more likely to express negative views about the rule commented on. 87 percent of such letters express negative views, compared to 59 percent for letters representing a non-publicly traded firm.

A given company's managers or directors may be signatories to multiple letters and a total of 395 publicly traded firms are represented among the corporate letters. To ease the interpretation of our results, in our groups of lobbying firms below we omit letters from corporations expressing neutral or positive opinions, as there are too few such letters to allow a separate analysis of these firms. ${ }^{10}$ Of the 395 publicly traded firms that are represented among the corporate letters, 288 firms are thus classified as lobbying against 'Enhanced Disclosure' and/or 'Corporate Responsibility', and/or 'Auditor Independence'. ${ }^{11}$

With regards to the other types of letter writers, the majority of accountants and lawyers argued against the rules they commented on, while opinions of academics and others were more mixed. The negative views of accountants and lawyers often refer to cases where the letter writer points out practical complexities of the rule commented on, or where auditors lobby against regulation that restricts the advisory role of auditing firms.

\section{B. Predictability Of Lobbying By Corporate Insiders}

Since most lobbying took place after the passage of SOX, our research design implicitly assumes that lobbying is, at least to some extent, predictable by investors. If not, we would not expect to observe different returns between lobbying firms and matched non-lobbying firms during the period leading up to passage of SOX. The fact that we do find different returns between the two groups by itself provides evidence that this assumption is reasonable.

Two additional analyses further support this assumption underlying our research design. First, a simple probit model indicates that lobbying is to some extent predictable based on observable

\footnotetext{
${ }^{9}$ In our subsequent returns analysis we will include a measure of insider stock ownership to control for differences in the incentives of insiders to lobby on shareholders' behalf.

${ }^{10}$ If a firm submits comments on several rules within a major rule category (i.e. several rules within 'Enhanced Disclosure') we classify them as lobbying against this major rule category only if all submitted comments are negative.

${ }^{11}$ The difference between the 395 and the 288 firms is driven by firms with neutral/positive letters and by the firms who only comment on the SEC's proposed rule on Security Holder Director Nominations discussed above.
} 
variables known at the start of our sample. Second, a firm-level event study reveals no abnormal returns for lobbying firms around the date of submission of a letter to the SEC, suggesting that lobbying does not come as a surprise to the market.

\section{B.1. Probit Models of Lobbying}

We begin by demonstrating that it is possible to predict to a certain extent which firms will lobby based on firm characteristics at the start of our sample. We run probit regressions where the dependent variable is an indicator variable taking a value of one if the firm lobbied the SEC against a SOX-related provision, and zero otherwise. We estimate the probit models separately for each of the three major rule categories. We include a variety of variables that may predict lobbying.

Larger firms may feel they are more likely to be able to influence the SEC rule makers; if there is a fixed cost element to lobbying, they may also incur lower relative costs of lobbying. In addition, to lobbying, insiders of larger firms may be extracting more resources and thus have a stronger incentive to try and weaken the implemented rules. As a measure of size, we include the natural logarithm of firm book assets. Similarly, firms with more profits for insiders to expropriate may be more likely to lobby. For each firm, we calculate the ratio of net income to sales as of the end of the 2000 fiscal year as a measure of profitability. ${ }^{12}$ Firms with more entrenched management may be more affected by SOX and may therefore be more likely to lobby. To capture this, we include the governance index of Gompers, Ishii and Metrick (2002). Higher values of this index indicate more managerial entrenchment. ${ }^{13}$ We also include the number of years the firm has been publicly traded as a measure of firm age. Firms that have a political action committee (PAC) may tend to be involved in all types of political and lobbying activities. We therefore include an indicator variable equal to one if the firm has a political action committee which was registered with the Federal Election Commission at some point during the period 1999-2000. Similarly, evidence of past lobbying may be indicative of future lobbying. We include an indicator variable equal to one if the firm lobbied the SEC in regards to the 1992 compensation reform analyzed by Lo (2003), and an indicator variable equal to one if the firm lobbied the SEC in regard to a contemporaneous 1992 rule on proxy fights. ${ }^{14}$ Higher institutional ownership may indicate the firm is better governed ex-ante,

\footnotetext{
${ }^{12}$ We use 2000 (as opposed to 2001) data since 2001 net income may only be disclosed in the first half of 2002 and could thus directly affect returns. The reported measure is winsorized at the $2 \%$ level, however our results are not sensitive to variation in the winsorization cutoff.

${ }^{13}$ All reported results are robust to substituting the Bebchuk, Cohen and Ferrell (2004) index for the Gompers, Ishii and Metrick (2002) index.

${ }^{14}$ Data on both these variables was obtained from Kin Lo. The proxy rule is described in further detail by Bradley,
} 
and therefore less likely to be affected by SOX. To capture this, we include the fraction of shares outstanding owned by institutions in 2001 as reported by the Thomson Financial CDA/Spectrum Institutional Holdings database. Since lobbying may be driven by compliance costs, we additionally include the log of audit fees paid in 2001. ${ }^{15}$ High pre-SOX audit fees may be associated (positively or negatively) with SOX compliance costs. To capture the complexity of the firm (which could affect both compliance costs and the impact of the rules on management behavior), we calculate the number of business segments and geographical segments from Compustat in year 2001. Finally, to capture the incentives of insiders to lobby on behalf os shareholders, we include the fraction of shares outstanding owned by the top executives of the firm in 2001 as reported by ExecuComp. ${ }^{16}$ Summary statistics for these variables are included in Table II.

Table III presents the results of the probit models for lobbying against the three types of SOX-related provisions. We present three specifications for each category of provisions. The first specification includes the independent variables described above. The second specification examines the extent to which lobbying is predictable based solely on characteristics that have been systematically shown to relate to returns: market capitalization (calculated at the end of week 6 of 2002), and book-to-market ratio (calculated using book value of equity at the end of fiscal year 2001 and market equity at the end of week 6 of 2002). The third specification includes all of the variables from the previous two specifications, allowing us to examine the predictive power of our independent variables above and beyond the systematic return-related characteristics. All three specifications include industry controls at the 1-digit SIC level. We set a variable to zero if data is missing and include indicator variables for missing data (the coefficients on these indicators are omitted from the table).

Given the summary statistics presented in Table II, it is not surprising to see in Table III that size is a strong predictor of lobbying. A second strong predictor of lobbying is profitability; firms with higher ratios of net income to sales are significantly more likely to lobby. Note that of the other regressors included, firm age is a significant predictor of lobbying against an 'Enhanced Dis-

\footnotetext{
Brav, Goldstein and Jiang (2006).

${ }^{15}$ Data on audit fees is obtained from Audit Analytics.

${ }^{16}$ In unreported results, we also include three additional variables that may indicate poor firm governance. Following Chchaochcharia and Grinstein (2005), we include an indicator variable taking the value of one if the firm's CEO has sold a large amount of stock within the 3-month period leading up to a large reported drop in earnings, and an indicator variable for restated earnings during 1998-2001. Data for both these variables was provided by Yaniv Grinstein and Vidhi Chhaochharia. Further, we include a measure of discretionary accruals calculated using the modified Jones (1991) model, which is intended to measure earnings management. These variables provide little predictive power in our models, and for brevity, are omitted from our reported results.
} 
closure' rule, while past lobbying regarding proxy rules and institutional ownership are significant predictors of lobbying against a 'Corporate Responsibility' rule. Such differential predictive ability of the variables will allow us to bolster our subsequent returns analysis by employing additional specifications that use predicted rather than actual lobbyers.

Psuedo R-squares for the models range from 27 percent for 'Enhanced Disclosure' to 36 percent for 'Corporate Responsibility,' suggesting that while our models can predict a sizeable amount of the variation in lobbying activity, there are other variables driving lobbying which we are unable to observe or model. It is likely that market participants had more detailed information about firm characteristics, and thus that they were able to predict more accurately than our probit models which firms would lobby (or more generally, which firms would be more affected by SOX).

\section{B.2. Event Study of Returns Around Date of Comment Letter}

To further ascertain whether investors indeed could predict ex-ante who the lobbying firms would be, we supplement the probit results with an event study of whether abnormal returns were observed around the date of the submission of a letter by a given company (and posting of the letter on the SEC web page or accessibility of the letter in the SEC's public reference room).

We examine an event period of 21 weeks $([-10,+10])$ surrounding the submission of a letter to the SEC. If a firm wrote multiple letters (e.g. lobbying against more than one rule in a given category), we include an observation for each of the letters, so long as there is no overlap of the 21 -week event period $[-10,+10]$. When letter event periods for the same firm overlap, we use only the first of the overlapping letters. We examine two sets of abnormal returns, with and without factor adjustment. For the returns with no factor adjustment, we first average the excess returns for lobbying firms relative to their matched non-lobbying firms across the set of lobbying firms. This is done for each week in event time where date zero in event time is the week the letter was filed with the SEC. Average excess returns are then summed over time (in event time) starting 10 weeks before the event date, and ending 10 weeks after the event date. ${ }^{17}$ For the factor-adjusted returns, we follow the same approach, except that the excess return for a given lobbying firm relative to its group of matched non-lobbying firms is replaced by the residual from a regression (run on the post-SOX period from week 31 of 2002 to the end of 2004) of the excess return on the market factor, size factor and book-to-market factor. Matching of lobbying and non-lobbying firms is done

\footnotetext{
${ }^{17}$ We omit letters filed within the first 10 weeks of SOX passage such that our event study is not affected by the news of SOX passage itself.
} 
in three ways: 100 size portfolios, 25 size and 5 book-to-market portfolios, and 25 size and 10 1-digit industry portfolios. We describe our matching approach in more detail below.

Figure 1 illustrates the findings of our event study and includes results for all three major rule categories. The graphs show results for abnormal returns measured relative to a group of nonlobbying firms constructed based on 100 size-portfolios. The results based on matching on size and book-to-market equity or size and industry are similar. If lobbying was not predictable by the market, we would expect to see a positive or negative reaction to the submission of a letter. Figure 1 reveals no such reaction, suggesting that market participants were not surprised to learn which firms lobbied.

\section{Returns of Lobbying and Non-Lobbying Firms During the Period Leading up to Passage of the Sarbanes-Oxley Act}

We now turn to the comparison of returns for lobbying and non-lobbying firms. Under the improved disclosure and governance hypothesis, returns should be larger for lobbying firms than for nonlobbying firms during the period leading up to passage of SOX. The compliance cost view of SOX has the opposite prediction.

\section{C.1. Portfolio Level Returns}

To test these two competing hypotheses, we must first decide precisely how the comparison between the two sets of firms should be made. The standard approach for this type of analysis is to calculate excess returns for a portfolio of the affected firms (here lobbyers) over and above the returns for a portfolio of control firms (here non-lobbyers). To do this calculation, one must decide on which characteristics lobbying and non-lobbying firms should be matched, and how fine a grid should be used to match along a given dimension.

A large literature documents that small firms (measured by market value of equity) and firms with high book-to-market equity ratios on average tend to outperform large firms and firms with low book-to-market ratios. Furthermore, in a particular time period, realized returns could differ systematically across firms with different size, book-to-market, industry, or other characteristics,

and such patterns may be entirely unrelated to the effects of SOX. It is therefore important to compare lobbying and non-lobbying firms with similar characteristics along these dimensions. Of course, there is a limit to how many characteristics one should match lobbying and non-lobbying firms on. In the extreme, if one matched along all observable dimensions related to disclosure, 
governance and variables measuring likely SOX compliance costs, then it may be more or less random which firms of a particular set of such characteristics decided to lobby the SEC. Such a matching scheme would then, by construction, find no different return patterns between lobbyers and non-lobbyers and would wrongly lead to the conclusion that SOX was irrelevant for firm value. Based on these considerations, we will consider a variety of approaches to match lobbying and nonlobbying firms on size, book-to-market, and industry (the leading variables known to be related to expected returns or likely to be related to realized returns for reasons not related to SOX), but will not match on variables directly related to disclosure, governance or likely compliance costs. Data on returns, industry and market capitalization are obtained from CRSP, while data on book equity values are obtained from COMPUSTAT.

To decide how best to do the matching on size, book-to-market, and industry, we return to Table II, which tabulates the characteristics of lobbying and non-lobbying firms. For each characteristic, we provide p-values for t-tests for equal means across the two groups. The statistics for nonlobbyers refer to firms who did not lobby for or against any SOX provision and are therefore identical for Panel A, which compares firms who lobbied against any of the 'Enhanced Disclosure' rules to non-lobbyers, Panel B, which compares firms who lobbied against any of the 'Corporate Responsibility' rules to non-lobbyers, and Panel C, which compares firms who lobbied against the ‘Auditor Independence' rule to non-lobbyers.

The strongest difference between the three groups of lobbyers and the non-lobbyers is that lobbying firms tend to be much larger than non-lobbying firms. Along the book-to-market equity dimension there is little difference between firms that lobby against 'Enhanced Disclosure' or 'Auditor Independence' and non-lobbyers, while firms that lobby against 'Corporate Responsibility' have significantly higher mean (but not median) book-to-market ratios than non-lobbyers. The industry composition of lobbyers and non-lobbyers differs somewhat, with significant differences for several industry categories. Together these statistics suggest that a fine grid along the size dimension is the most important for ensuring that the matched non-lobbying firms have characteristics similar to those of the lobbying firms. We therefore show results for three approaches, defined by how many comparison portfolios of non-lobbying firms we construct: (a) 100 size-sorted portfolios (with NYSE break points to set a finer grid at the top end), (b) 125 size and book-to-market sorted portfolios defined as the interaction of 25 size categories $^{18}$ and 5 book-to-market categories, and (c)

\footnotetext{
${ }^{18}$ In defining the 25 size portfolios, we use increments of seven percentiles for portfolios up to the 70th percentile. For the remaining portfolios, we use increments of 2 percentiles, to allow for a finer grid at the top of the range.
} 
250 size and industry sorted portfolios, defined as the interaction of 25 size categories (with NYSE break points) and 10 1-digit SIC industry code categories. ${ }^{19}$

For each approach, we first calculate the weekly average portfolio returns for each of the 100/125/250 comparison groups of non-lobbying firms. We then calculate the average weekly excess return for lobbying firms over and above their matched non-lobbying firm portfolio as

$$
\frac{1}{N_{t}} \Sigma_{i=1}^{N_{t}}\left(r_{i, t}^{\text {Lobby }}-r_{p, t}^{\text {Non-Lobby }}\right)
$$

where $r_{i, t}^{L o b b y}$ is the return on lobbying firm $i$ 's stock in week $t, N_{t}$ is the number of lobbying firms for which returns are available for week $t$, and $r_{p, t}^{\text {Non-Lobby }}$ is the average weekly return in week $t$ on the portfolio of non-lobbying firms matched to firm $i$.

If the matching succeeds in lining up each lobbying firm with a set of non-lobbying firms with very similar size, book-to-market and industry characteristics, then the above excess return time series directly measures the abnormal performance $(\alpha)$ of lobbyers. If the match is less accurate, more precise measures of the abnormal part of any over- or under-performance of lobbyers can be obtained by estimating a factor model and analyzing the $\alpha$ from such a model. We present both the results which do not use a factor model and the results which use a 3-factor model and regress the excess return of lobbyers on the weekly market factor (MKT), size factor (SMB), and book-to-market factor (HML) calculated from daily factor data from Ken French's web page:

$$
\frac{1}{N_{t}} \Sigma_{i=1}^{N_{t}}\left(r_{i, t}^{\text {Lobby }}-r_{p, t}^{N o n-L o b b y}\right)=\alpha+\beta_{M K T}\left(r_{M K T, t}-r_{f, t}\right)+\beta_{S M B} r_{S M B, t}+\beta_{H M L} r_{H M L, t}+\epsilon_{i, t}
$$

where $r_{f}$ is the riskless (30-day T-bill) rate and $\epsilon$ is an error term. ${ }^{20}$ To the extent that results differ depending on whether a factor model is used, one would expect those from the factor model to be the most accurate.

Table IV Panel A shows the estimates of abnormal performance of lobbyers relative to nonlobbyers during the 24-week period leading up to passage of SOX, beginning in week 7 of 2002 and ending in week 30 of 2002 (February 8, 2002 to July 26, 2002). The top part of the panel shows strong evidence of positive abnormal returns for firms whose insiders lobbied against one of the 'Enhanced Disclosure' provisions, relative to their matched sample of non-lobbyers. Without factor

\footnotetext{
${ }^{19}$ In all cases we define break points using the full set of lobbying and non-lobbying firms. Size is defined as market value of equity at the beginning of the week, and is updated weekly. Book-to-market equity ratio is calculated using book equity for the prior calendar year from COMPUSTAT and market equity for the beginning of the year (with the exception that we for 2002 use market equity in week 6 of 2002).

${ }^{20}$ Weekly data are used as opposed to daily data to avoid any potential biases in factor loadings due to differential liquidity of the stocks of lobbying and non-lobbying firms. An alternative would be to use daily data but include lags of the factors as regressors.
} 
controls, the weekly alphas in columns (1), (4), and (7) are 0.0051, 0.0042, and 0.0033 across the three methods of matching. This corresponds to total abnormal returns for such lobbyers of 12.1, 10.2, and 7.9 percent over the 24 -week period leading up to SOX passage. In each case, the alphas are statictically significantly different from zero at the one percent level. Results are a bit weaker when a factor model is used (columns (3), (6) and (9)). A potentially important issue with the factor model is that if we were to estimate the factor loadings using only 24 weeks of data, this could lead to overfitting and corresponding downward small sample bias in the estimated abnormal excess returns (alphas). Instead, we use the full time period from week 7 of 2002 to the end of 2004 and allow for different alphas for the period leading up to SOX passage and the post-passage period. The alphas from the factor models in columns (3), (6) and (9) imply total abnormal returns for such lobbyers of 11.8, 9.6, and 8.4 percent over the 24 -week period leading up to SOX passage. ${ }^{21}$

Figure 2 illustrates the cumulative abnormal returns over time for firms that lobbied against an 'Enhanced Disclosure' provision of SOX. It is based on portfolio level returns and three sets of cumulative abnormal returns are shown. The first of the three is based on the size-matched control groups of non-lobbying firms, the second on the size and book-to-market equity matched control groups and the third on the size and industry-matched control groups. In each graph, two lines are shown. The unadjusted cumulative abnormal return is calculated by averaging the excess returns over the comparison group across lobbying firms in each week, and then summing these abnormal returns over time, starting in week 7 of year 2002. The factor-adjusted cumulative abnormal return is calculated by first regressing the excess return over the comparison group on the excess return on the market, and the Fama-French size and book-to-market factors. The regression is run using weekly data from week 7 of 2002 until the end of 2004, and the intercept (alpha) plus the residuals are averaged each week and then summed over time. The two vertical lines indicate the beginning and end of the 24-week period leading up to SOX passage. It is striking how the abnormal performance of lobbying firms relative to non-lobbying firms ends right around the time of the passage of SOX. This pattern further reassures us that we are indeed measuring the impact of the law on lobbying firms.

The middle and bottom parts of Table IV Panel A repeat the same regressions, but now focusing on firms who lobbied against a 'Corporate Responsibility' or 'Auditor Independence' rule. Here, the evidence for abnormal positive excess returns for lobbying firms relative to their matched non-

\footnotetext{
${ }^{21}$ We discuss the alphas for the post-passage period below.
} 
lobbying firms is statistically weaker than for firms who lobbied against an 'Enhanced Disclosure' rule.

As mentioned earlier, an alternative to using lobbying as a proxy for being more affected by SOX is to instead sort firms based on their predicted probability of lobbying based on ex-ante characteristics. As previously discussed, there are numerous advantages to a research design that employs lobbying rather than its predictors. A major disadvantage of the predicted lobbyer approach is that we as econometricians likely employ many fewer firm characteristics than market participants in predicting which firms will be more affected by SOX. An advantage of this approach, however, is that it does not rely on the assumption that market participants could predict precisely which firms would lobby after the passage of SOX.

Panel B of Table IV repeats the analysis in Panel A, substituting firms predicted to lobby by our probit model for the actual lobbyers, where predicted lobbyers are those firms whom our probit models place in the top 3\% of firms based on likelihood of lobbying. Once again, the top part of the panel presents strong evidence of positive abnormal returns for firms that our probit model predicts should lobby against one of the 'Enhanced Disclosure' provisions, relative to their matched sample of non-lobbyers. Without factor controls, the weekly alphas in columns (1), (4), and (7) are $0.0044,0.0049$, and 0.0027 across the three methods of matching. This corresponds to total abnormal returns for such lobbyers of 10.6, 11.8, and 6.5 percent over the 24 -week period leading up to SOX passage. The returns implied by the factor models in columns (3), (6) and (9) are larger: 12.0, 14.4, and 8.9 percent over the 24-week period leading up to SOX passage. In 8 out of 9 specifications in the panel, the alphas are significantly different from zero at the 10 or 5 percent level.

Figure 3 illustrates the cumulative abnormal returns over time for firms predicted to lobby against an 'Enhanced Disclosure' provision of SOX, and is constructed in a similar manner to Figure 2. As in Figure 2, which looks at the abnormal returns of lobbying firms relative to nonlobbying firms, the abnormal performance of predicted lobbyers relative to non-lobbying firms ends right around the time of the passage of SOX.

The middle and bottom parts of Table IV Panel B repeat the same regressions focusing on firms who were predicted by our probit model to lobby against a 'Corporate Responsibility' or 'Auditor Independence' rule. The evidence for abnormal positive excess returns for predicted lobbyers relative to their matched non-lobbying firms for these two sets of rules is again statistically 
weaker than for firms who were predicted to lobby against an 'Enhanced Disclosure' rule.

Interpreting the portfolio-level results presented in Table IV is not straightforward, however. Over 40 percent of the firms that lobbied against an 'Auditor Independence' provision also lobbied against at least one 'Enhanced Disclosure' provision, and 36 percent of firms that lobbied against a 'Corporate Responsibility' provision also lobbied against at least one 'Enhanced Disclosure' provision. To address this issue, we proceed to estimate the separate abnormal returns associated with each of the three major rule categories by running firm-level return regressions.

\section{C.2. Firm-Level Returns}

We run firm level (as opposed to portfolio-level) regressions of the following form:

$$
\begin{aligned}
\Sigma_{t=1}^{T}\left(r_{i, t}^{\text {Lobby }}-r_{f, t}\right)= & \delta_{0}+\gamma_{1} I(\text { Lobbied Against Enhanced Disclosure Rules }) \\
& +\gamma_{2} I(\text { Lobbied Against Corporate Responsibility Rules }) \\
& +\gamma_{3} I(\text { Lobbied Against Auditor Independence Rule })+X_{i}^{\prime} \beta+u_{i}
\end{aligned}
$$

where $\mathrm{I}($.$) indicates a dummy variable, \delta_{0}$ is an intercept term, $X$ is a set of control variables and $u_{i}$ is an error term. The regression is run on the full set of firms, i.e. including both lobbyers and nonlobbyers, and has one data point per firm. In regressions (1), (2), and (3) of Table V Panel A, the dependent variable is the sum of the weekly excess returns over the riskless rate during the period leading up to SOX passage. The regression coefficient $\gamma$ on the dummy variable for a particular type of lobbying estimates how much the cumulative weekly excess return during the period differs between that group of lobbying firms and a typical non-lobbying firm. To control for differences between lobbying and non-lobbying firms along size, book-to-market, and industry dimensions, and for similarity to the portfolio-level analysis presented in Table IV, we include indicator variables for 100 size, 25 size and 5 book-to-market, or 25 size and 10 1-digit industry portfolios, depending on the specification. Table V Panel A presents our estimates for lobbying firms, while Panel B presents the estimates for predicted lobbyers.

Regressions (1), (2) and (3) of Table V Panel A indicate that the market expected SOX to benefit the firms most affected by its 'Enhanced Disclosure' provisions (as evidenced by their lobbying), with only small added shareholder value for firms most affected by its 'Corporate Responsibility' or 'Auditor Independence' provisions. The abnormal excess return for firms lobbying against an 'Enhanced Disclosure' rule captured by the $\gamma_{1}$ coefficient indicates a total abnormal excess return for the lead-up period of between 8.6 percent and 13.2 percent across the three regressions. These 
effects are comparable (theoretically, and in magnitude) to the effects estimated based on the alpha $a_{\text {Lead-Up }}$ coefficient in the top part of Panel A. The $\gamma_{2}$ coefficient on lobbying against a 'Corporate Responsibility' rule indicates little abnormal excess return (economically or statistically) for the lead-up period across the three regressions. The $\gamma_{3}$ coefficient on lobbying against the 'Auditor Independence' rule indicates a total abnormal excess return for the lead-up period of between 3.3 percent and 4.0 percent across the three regressions, but with no statistical significance at conventional levels.

We obtain similar results in Panel B of the table, where we replace the indicator variables for lobbying with indicator variables for being predicted to lobby according to the probit model in Table III. Being predicted to lobby against an 'Enhanced Disclosure' provision implies a total abnormal excess return for the lead-up period ranging from 6.2 percent to 12.6 percent across the three specifications; no statistically significant excess return is implied by being predicted to lobby against a 'Corporate Responsibility' or 'Auditor Independence' provision.

In sum, the results of Tables IV and V support the positive view of SOX, and suggest that investors expected the legislation to increase shareholder value. In particular, the return results indicate that firms most affected by the 'Enhanced Disclosure' provisions of SOX (as evidenced by their lobbying) experienced positive abnormal excess returns during the period leading up to SOX passage of around 10 percent relative to less affected (non-lobbying) firms with similar size, bookto-market and industry characteristics. There is little effect experienced by firms most affected by the 'Corporate Responsibility' and 'Auditor Independence' rules.

\section{Returns During the Period Following Passage of the Sarbanes-Oxley Act}

From Figure 2, it is apparent that firms lobbying against one or more of the SOX 'Enhanced Disclosure' rules had returns during the post-SOX period that were fairly similar to those of their matched comparison group of non-lobbying firms. Tables IV and V confirm this result. Columns (2)-(3), (5)-(6) and (8)-(9) of Table IV Panel A estimate the portfolio level excess return regressions on the full period from week 7 of 2002 to the end of 2004, with separate intercepts ( $\alpha$ 's) for the leadup period and the post-passage period, while Panel B presents similar analysis for predicted lobbyers relative to matched non-lobbyers. In the top part of the panel, which concerns 'Enhanced Disclosure,' the intercept for the post-passage period, alpha $a_{\text {Post }}$, is consistently close to zero in both economic and statistical terms. Similar results obtain in columns (4)-(6) of Table V Panels A (lobbyers) and B (predicted lobbyers) at the firm-level in the post-passage period: the $\gamma_{1}$ regres- 
sion coefficient of the dummy variable equal to one for firms that lobbied against an 'Enhanced Disclosure' rule is close to zero. These findings indicate that the returns for firms that lobbied (or were predicted to lobby) against an 'Enhanced Disclosure' rule were similar to the returns for their non-lobbying comparison group of firms, and thus that the increase in (relative) stock prices experienced by lobbying firms (or predicted lobbyers) did not tend to reverse during the post-passage period, suggesting that the positive expectation of shareholders evidenced by thier letters to the SEC and by returns in the pre-passage period were warranted.

\section{E. Section 404: Assessment of Internal Controls}

Among the most controversial and most discussed elements of SOX is Section 404 of the Act, which deals with management assessment of internal controls. Section 404 is a component of Title IV of the Act, and thus is part of the 'Enhanced Disclosure' rules in our analysis. Since our research design allows us to examine shareholders' reactions to individual elements of SOX, it is a worthwhile exercise to ask whether the results presented above are robust to focusing on this particular provision alone. To do so, we repeat the analysis above, limiting our group of lobbying firms to those that lobbied specifically against the rules related to Section 404.

The results, presented in graphic form in Figure 4, are striking. Firms that lobby against rules related to Section 404 specifically experience an abnormal excess return over the 24 weeks leading up to the passage of the Act of similar magnitude to that evidenced when we considered all firms that lobby against any of the 'Enhanced Disclosure' rules. Once again, these excess returns appear to end almost exactly around the passage of SOX, and do not revert away in the post period.

The results in Figure 4 suggest that investors believed that Section 404 specifically would increase shareholder value, and support the arguments presented in Coates (2006), who suggests that the enhanced disclosure related to Section 404 was one of the most important elements of the Act. $^{22}$

\section{Interpretation and Discussion}

\section{A. Mechanism}

The results from our analysis in the previous section suggest that that shareholder's perceptions of SOX were positive, and that these perceptions were reflected in the relative returns of more and less

\footnotetext{
${ }^{22}$ A firm-level analysis with two separate indicator variables for lobbying against Section 404-related rules and against other 'Enhanced Disclosure' rules reveals roughly equal impact for the two sets of rules.
} 
affected firms. What then are the mechanisms through which SOX might be expected to increase shareholder value?

There are three primary channels through which SOX may affect shareholder value. First, SOX may directly improve the operating performance of the firm through the elimination of management ineptness, complacency or the improvement of operations as a result of lessons learned during the internal control review. Second, SOX may improve operating performance through the elimination of actual stealing or perquisite consumption on the part of managers who are now subject to greater disclosure and transparency. Third, SOX may lead to an increase in shareholder confidence that is reflected in a lower cost of capital.

Evaluating these mechanisms is difficult. There is no clear manner in which to ascertain if SOX has effectively lowered the discount rate used by shareholders. We can attempt to evaluate the change in operating performance of lobbying firms relative to matched non-lobbyers comparing the pre-SOX and post-SOX periods. In unreported results, we measure changes in operating performance as (Operating income in 2004-Operating income in 2001)/(Market value of equity at the end of week 6 of 2002), where operating income is COMPUSTAT Item 13 (operating income before depreciation). We then run firm level regressions with one observation per firm and with controls for size portfolio dummies, size and book-to-market portfolio dummies, or size and industry portfolio dummies. The estimates from our models suggest that firms that lobbied against an 'Enhanced Disclosure' rule experience an improvement in operating income relative to initial market value of equity of about 5 percentage points, and this effect is statistically significant at the 1 percent level. When we repeat the same regressions substituting predicted lobbyers for actual lobbyers, we find similar results, though the magnitudes are sensitive to the type of controls included.

These results, on the one hand, provide some reassurance that our return results are consistent with changes in profitability, but they are not a valid test of the mechanism through which SOX may have affected shareholder value. Our results in the previous section indicate that profitability is a strong predictor of lobbying, thus inducing an endogeneity problem in any test that attempts to determine whether lobbying firms (or predicted lobbyers) have improved operating performance over the period in question. In this sense, analyzing operating performance is useful only in that finding a decrease in the performance of lobbyers relative to non-lobbyers would tend to rule out operating performance as the mechanism through which SOX affected returns. Finding and increase in operating performance does not provide a clean test suggesting operating performance is the 
mechanism, however, due to the endogeneity problem.

As discussed in Section II, we are able to address this endogeneity concern in our returns analysis above. Reverse causality in our setting would imply that there should be no significant differential in the excess returns of lobbying groups over and above similar non-lobbyers when comparing the preand post-passage periods. However, as we demonstrate, a significant differential of approximately $7 \%$ exists in the pre- and post-passage excess returns of lobbyers. This return differential suggests that being more affected by SOX leads to excess returns, rather than it simply being simply the case that better (or worse) performing firms tend to lobby, without necessarily being more affected by the legislation. We cannot use a similar approach to examine changes in operating performance for lobbying and non-lobbying groups in a causal fashion. While return data is available on a weekly basis, operating performance is only available to us on an annual basis, and thus does not allows us to examine whether there is a kink in performance around the date of SOX passage.

A second useful exercise is to attempt to ascertain the extent to which investor confidence has improved since passage of SOX. UBS/Gallup conducts an Index of Investor Optimism Poll, which provides an indication of investor confidence over the period spanning the passage and implementation of SOX. In May 2002, 60\% of respondents to the poll indicated that questionable accounting practices in business hurt the investment climate in the U.S. "a lot." By May 2006, that percentage had dropped to $39 \%$. Causal interpretation of such survey evidence is, however, not possible.

\section{B. Costs and Benefits to Shareholders}

Following the passage of SOX, a heated debate has emerged about the high costs of complying with the 'Enhanced Disclosure' provisions of SOX, notably Section 404's assessment of internal controls. It is widely acknowledged that the compliance costs associated with SOX have been higher than initially expected. In June 2003, the SEC estimated the aggregate cost of implementing Section 404 alone on all registrants at approximately $\$ 1.24$ billion, or $\$ 91,000$ per registrant. In January 2004, Financial Executives International (FEI) completed the first of a string of surveys estimating the cost of SOX, and Section 404 in particular. The survey placed the expected average total cost of SOX compliance at approximately $\$ 1.93$ million per company. Expected costs appeared to be increasing in firm size, with expected total compliance costs for larger firms (over $\$ 5$ billion in annual revenues) to reach $\$ 4.6$ million per company. A first follow-on survey by FEI in June 2004 raised these estimates to $\$ 3.15$ million and $\$ 8$ million per company, respectively. A second follow-on 
survey by FEI in March of 2005 raised the estimates to $\$ 4.36$ million and $\$ 10$ million, respectively.

How do these costs affect our analysis of the post-passage period? We note first that if compliance costs increased equally for all firms (as a fraction of market value), then our analysis of excess returns of lobbyers over lobbyers will be unaffected by the increase. This is an obvious shortcoming of a research design which compares more affected firms to less affected firms, without having a comparable group of firms unaffected by the legislation studied. We can only say that considering the full period from when serious discussions about the legislation first started in week 7 of 2002 to the end of 2004 (well into the implementation phase of SOX), the stocks more affected firms (identified as lobbying firms) outperformed those of less affected firms (identified as non-lobbying firms). Based on our returns analysis alone, we cannot unambiguously say that the net benefit of SOX for either group is positive.

What then can be said about the net benefit of SOX for shareholders of lobbying and/or nonlobbying firms? Our analysis of comment letters from investors and investor groups indicates that shareholders expected SOX to be value increasing on average across publicly traded firms. To our knowledge, shareholder support for SOX has not diminished since the period covered by the letters we analyze. For example, at the SEC's "Roundtable Discussion on Second-Year Experiences with Internal Control Reporting and Auditing Provisions" held on May 10, 2006, institutional investors expressed continued support for SOX, specifically for the section 404 on internal controls. In her statement dated March 1st, Ann Yerger from the Council of Institutional Investors (an association of more than 130 corporate, union, and public pensions plans with more the $\$ 3$ trillion in assets) wrote: "...the Council believes the benefits over time will far outweigh the costs and will be a positive for all involved in the U.S. capital markets. ... In closing, Section 404 is working."

Furthermore, based on our return results, and drawing on the survey evidence on SOX compliance costs, it can be argued more formally that the net benefit of SOX were positive for shareholders of lobbying firms. Assume that compliance costs are similar for lobbying and non-lobbying firms. ${ }^{23}$ Assume in addition that there was no gross benefit of SOX for lobbying firms (again, a conservative assumption). Under these two assumptions, the cumulative abnormal excess return of about 10 percent for firms lobbying against an 'Enhanced Disclosure' rule relative to their matched nonlobbying firms then implies that the gross benefit of SOX for these lobbying firms was about 10 percent of their initial market value, or approximately $\$ 329$ billion in total. It is unlikely that the

\footnotetext{
${ }^{23}$ This is likely to be a conservative assumption, as analysis of audit fees pre- and post-SOX indicates that fees rose more (relative to firm size) for lobbying firms than for non-lobbying firms over the period from 2001 to 2004.
} 
present value of SOX compliance costs for lobbying firms is as high as 10 percent of these firms initial market value. From Table II Panel A, the mean market value for firms lobbying against an 'Enhanced Disclosure' rule is $\$ 16.8$ billion, while the median is $\$ 2.7$ billion. We can compute the average SOX compliance cost for lobbying firms, using compliance costs estimates from the FEI 2006 survey, which breaks costs down by sales volume. This average cost is a little under $\$ 5$ million per firm. Using a discount rate of 10 percent, the present value of the average lobbying firm's compliance costs is then $\$ 50$ million. This corresponds to 0.3 percent of the mean market value of $\$ 16.8$ billion and 1.9 percent of the median market value of $\$ 2.7$ billion.

This admittedly simplified calculation suggests that, at least for the set of firms lobbying against an 'Enhanced Disclosure' rule, SOX was a net benefit of between 8.1 and 9.7 percent of initial market value. We have data for 196 such firms with a total market value of $196 \times \$ 16.8$ billion or a little under $\$ 3.3$ trillion. At a net benefit of 8.1 percent of market value, the total net benefit of SOX for these lobbying firms comes to $\$ 266$ billion. At a net benefit of 9.7 percent of market value, the total net benefit of SOX for these lobbying firms comes to $\$ 319$ billion.

We can also go one step further, and attempt to estimate the net benefit of SOX for shareholders of all those companies publicly traded as of the beginning of our event period. Under the conservative assumption that there was no (gross) benefit of SOX for non-lobbyers, the total benefit to shareholders from SOX is the gross benefit of SOX for lobbying firms, approximately $\$ 329$ billion in total. Based on compliance cost numbers by firm sales reported by the March 2006 FEI survey, the total estimated annual compliance costs for the full set of US publicly traded firms is approximately $\$ 14$ billion. $^{24}$ At a discount rate of 10 percent, the present value of these costs is $\$ 140$ billion; at a discount rate of 5 percent, the present value of these costs would be $\$ 280$ billion, still considerably less than the approximate gross benefit of $\$ 329 \mathrm{~B}$ to lobbyers alone. ${ }^{25}$ This suggests that with even a small positive gross benefit of SOX for non-lobbyers, the net benefit of SOX for the overall US stock market could be substantial.

\footnotetext{
${ }^{24}$ To calculate the total estimated annual compliance costs for publicly traded firms, we assign each firm the compliance cost number associated with FEI sales category its sales fall into in 2001. To estimate sales for firms with no sales data, we regress firm sales on the natural log of market capitalization and its square for firms that do have sales data. We then use the resulting regression estimates to predict sales for those firms with no sales data, and assign them the FEI compliance cost for their sales category based on their predicted sales. We then sum the compliance costs across firms.

${ }^{25}$ Some lobbying groups, in particular AeA (formerly the American Electronics Association), using their own internal estimates in addition to FEI data, suggest that total annual compliance costs for SOX will be higher, or approximately $\$ 29-\$ 35 \mathrm{~B}$. These groups tend to build these estimates using a per-firm cost estimate taken as the FEI estimate for large firms, rather than assigning each firm the cost estimate appropriate to its size and sales volume. Even at an annual cost estimate of $\$ 30 \mathrm{~B}$, the present value of the costs at a discount rate of $10 \%$ would still be roughly similar to the gross benefits for lobbying firms.
} 
Interpretation of these numbers, however, must be nuanced. Our calculations cannot account for loss of shareholder welfare due to the decisions of some previously public companies to delist due to the burdens of SOX regulation; nor can it account for any welfare loss resulting from the decisions of private companies to remain private or to go public on non-US exchanges (Zingales (2006)). In addition, we cannot rule out that insiders lost an amount equal to or greater than what outside investors gained. Additionally, it is important to note that the lobbying firms in our sample are predominantly large, established organizations, and thus our returns analysis does not provide specific conclusions as to the effect of SOX on smaller firms.

\section{Conclusion}

In this paper, we evaluate the impact of SOX on shareholders by analyzing the SOX-related lobbying behavior of corporations, individuals and organizations. We classify the rules on which the SEC solicited comments into three major categories: those related to 'Enhanced Disclosure', those related to 'Corporate Responsibility', and those related to 'Auditor Independence'. We then examine the comment letters sent to the SEC during the drafting of the final SOX rules.

We document that individual investors, as well as large investor groups such as pension funds and labor unions, were overwhelmingly in favor of the SOX provisions they commented on, speaking to shareholders' perceived value of the legislation. In contrast, our reading of letters to the SEC by corporate insiders reveals that an overwhelming majority of insiders in lobbying companies opposed the SOX provision they commented on. We then use lobbying by corporate insiders to distinguish between two views of SOX: the view that SOX improves governance and disclosure, and the view that SOX will not be beneficial due to high compliance costs outweighing any potential benefits. Our identifying assumption is that insiders in companies more affected by SOX (positively or negatively) were more likely to lobby.

Our study of returns reveals that during the 24-week period leading up to passage of SOX, returns were higher for corporations whose insiders lobbied against an 'Enhanced Disclosure' provision of SOX than for non-lobbying firms with similar size, book-to-market and industry characteristics. This lends support to the improved disclosure and governance hypothesis and suggests that corporate insiders lobbied to water down the implementation of SOX because SOX reduces insiders' ability to expropriate company resources. Cumulative returns were approximately 10 percent higher for corporations whose insiders lobbied against one or more of the SOX 'Enhanced Disclosure' pro- 
visions than for non-lobbying firms with similar size, book-to-market and industry characteristics. There is no evidence of differential returns between lobbyers and non-lobbyers in the post-passage period.

In sum, our findings suggest that investors had overwhelmingly positive expectations about the effects of SOX. These expectations appear to be warranted in the case of the 'Enhanced Disclosure' provisions of SOX, though not in the case of the 'Corporate Responsibility' or 'Auditor Independence' provisions. 


\section{REFERENCES}

Bebchuk, L., A. Cohen and A. Ferrell, 2004, "What Matters in Corporate Governance?", working paper, Harvard Law School and NBER.

Bloom, N. and J. Van Reenen, 2006, "Measuring and Explaining Management Practices Across Firms and Countries," wokring paper, London School of Economics.

Bradley, M. A. Brav, I. Goldstein and W. Jiang, 2006, "Costly Communication, Shareholder Activism and Limits to Arbitrage: evidence from Closed-End Funds", working paper, Duke University. Chhaochharia, V., and Y. Grinstein, 2005, "Corporate Governance and Firm Value: The Impact of the 2002 Governance Rules", Journal of Finance, forthcoming.

Coates, J. C., 2006, "The Goals and Promise of the Sarbanes-Oxley Act", Journal of Economic Perspectives, forthcoming.

Cohen, D. A., A. Dey, and T. Z. Lys, 2005, "Trends in Earnings Management and Informativeness of Earnings Announcements in the Pre- and Post-Sarbanes Oxley Periods", working paper, Kellogg School of Management.

Engel, E., R. M. Hayes, and X. Wang, 2004, "The Sarbanes-Oxley Act and Firms' Going-Private Decisions", working paper, University of Chicago.

Gompers, P., J. Ishii and A. Metrick, 2003, "Corporate Governance and Equity Prices," Quarterly Journal of Economics, February.

Greenstone, M.,P. Oyer and A. Vissing-Jørgensen, 2006, "Mandated Disclosure, Stock Returns, and the 1964 Securities Acts Amendments", forthcoming, Quarterly Journal of Economics.

Jones, J. J., 1991, "Earnings Managment During Import Relief Investigations," Journal of Accounting Research, 29, 193-228.

King, R. and T. O'Keefe, 1986, "Lobbying Activities and Insider Trading," The Accounting Review, $61,1,76-90$.

Lo, K., 2003, "Economic Consequences of Regulated Changes in Disclosure: The Case of Executive Compensation", Journal of Accounting and Economics, 35, 285-314.

Rezaee, Z. and P. Jain, 2003, "The Sarbanes-Oxley Act of 2002 and Security Market Behavior: Early Evidence", working paper, University of Memphis.

Zhang, I. X., 2005, "Economic Consequences of the Sarbanes-Oxley Act of 2002", working paper, University of Rochester. 
Zingales, L., 2006, "Is the U.S. Capital Market Losing its Competitive Edge?", forthcoming, Journal of Economic Perspectives. 


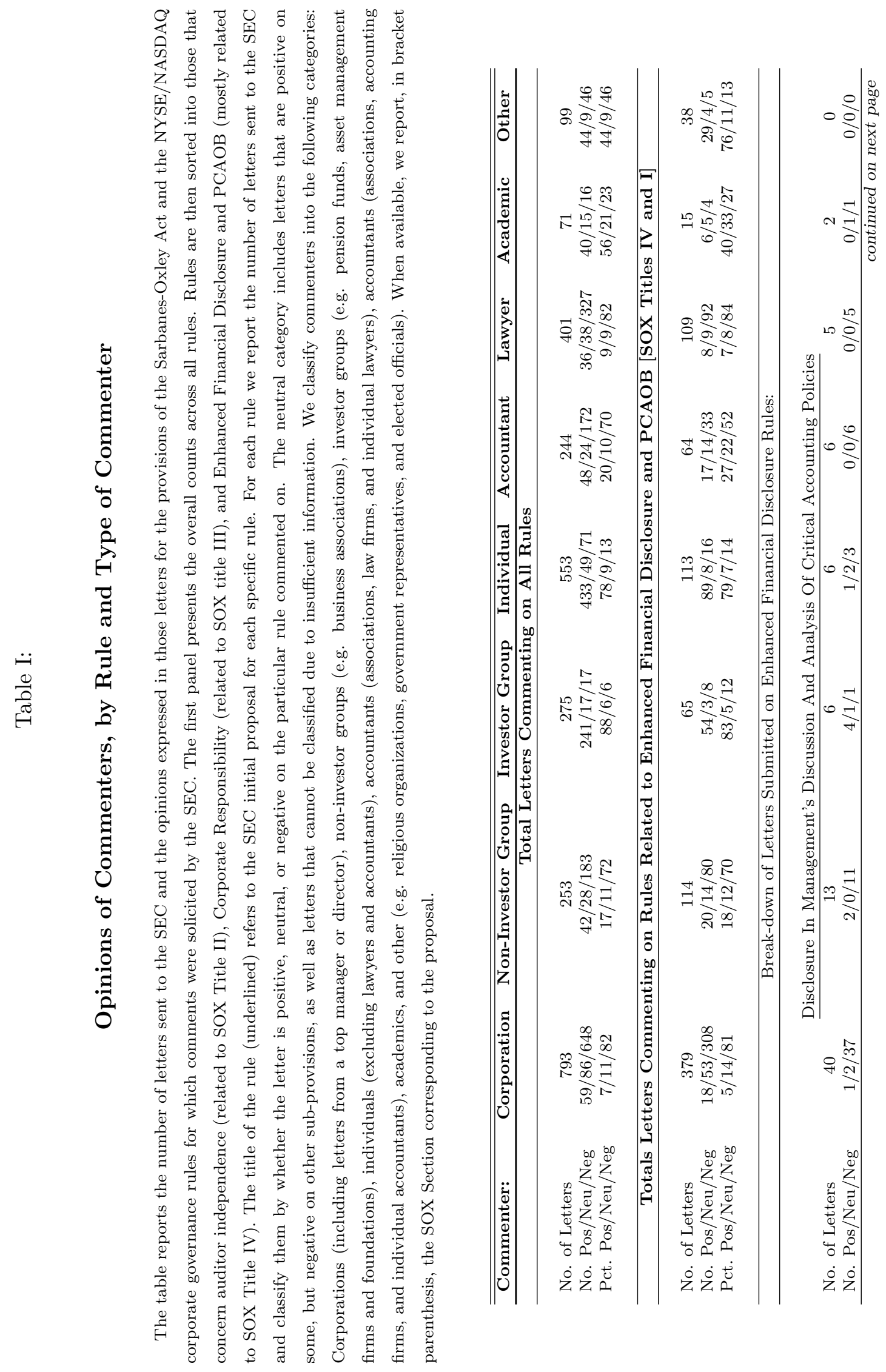




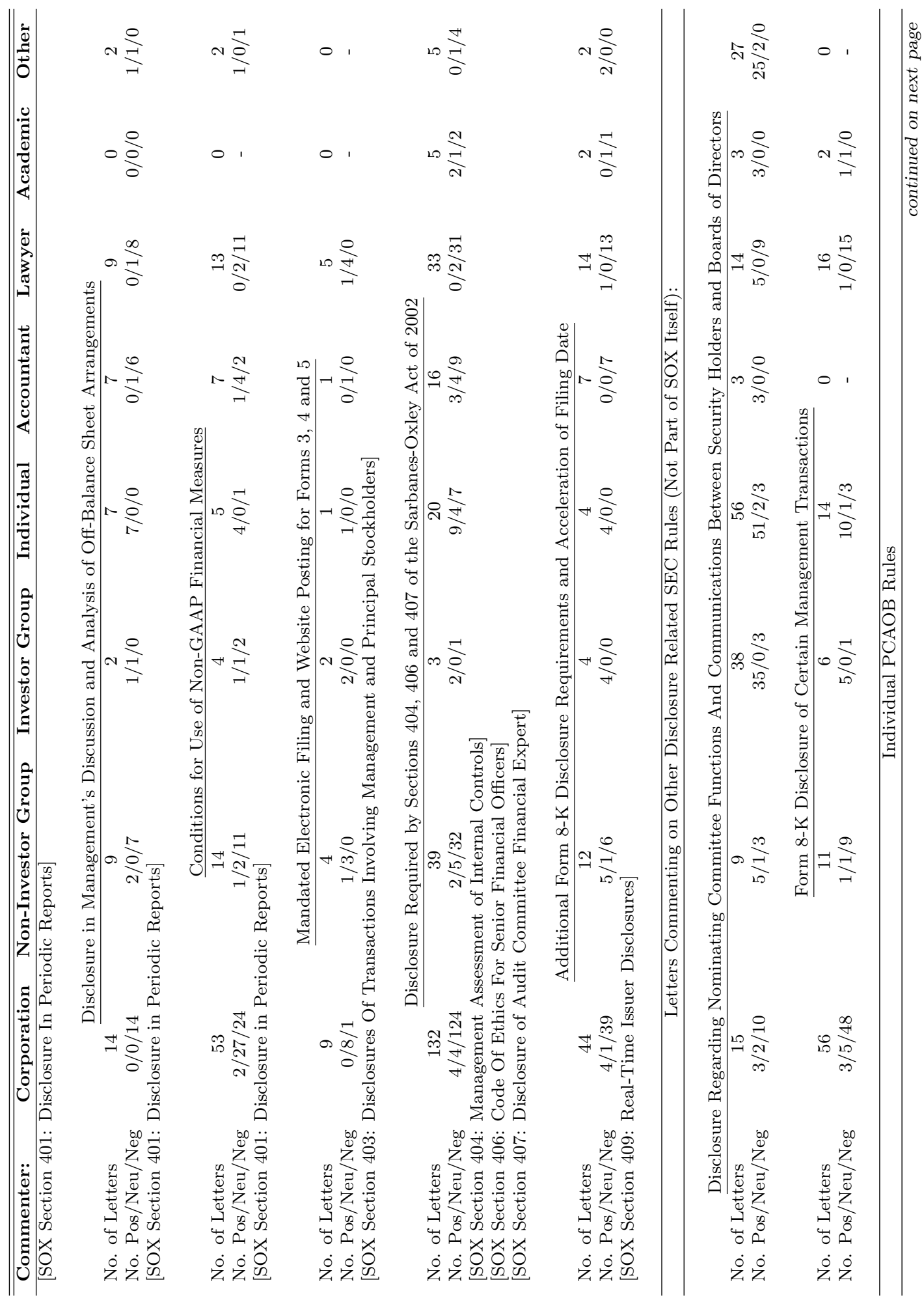




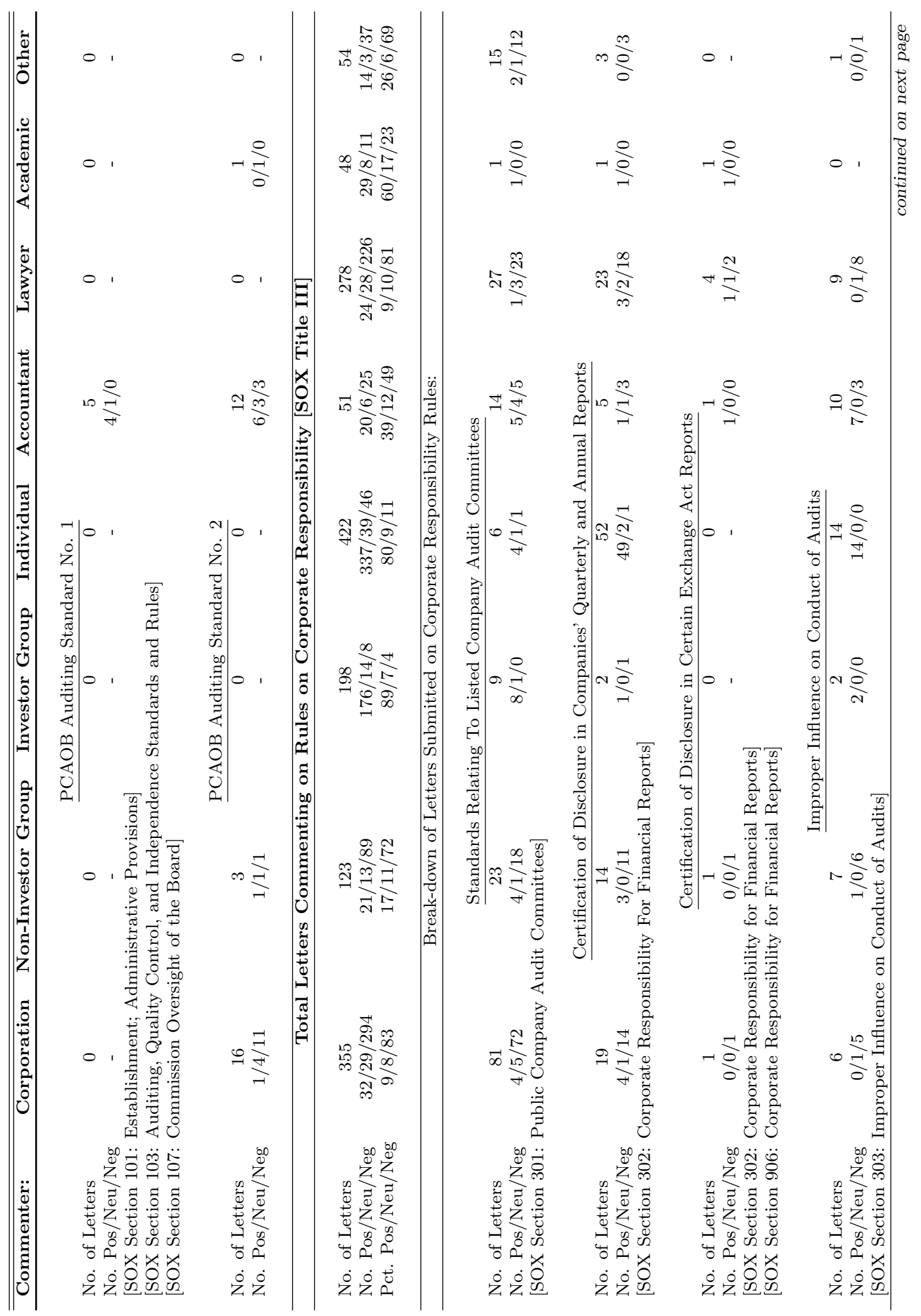




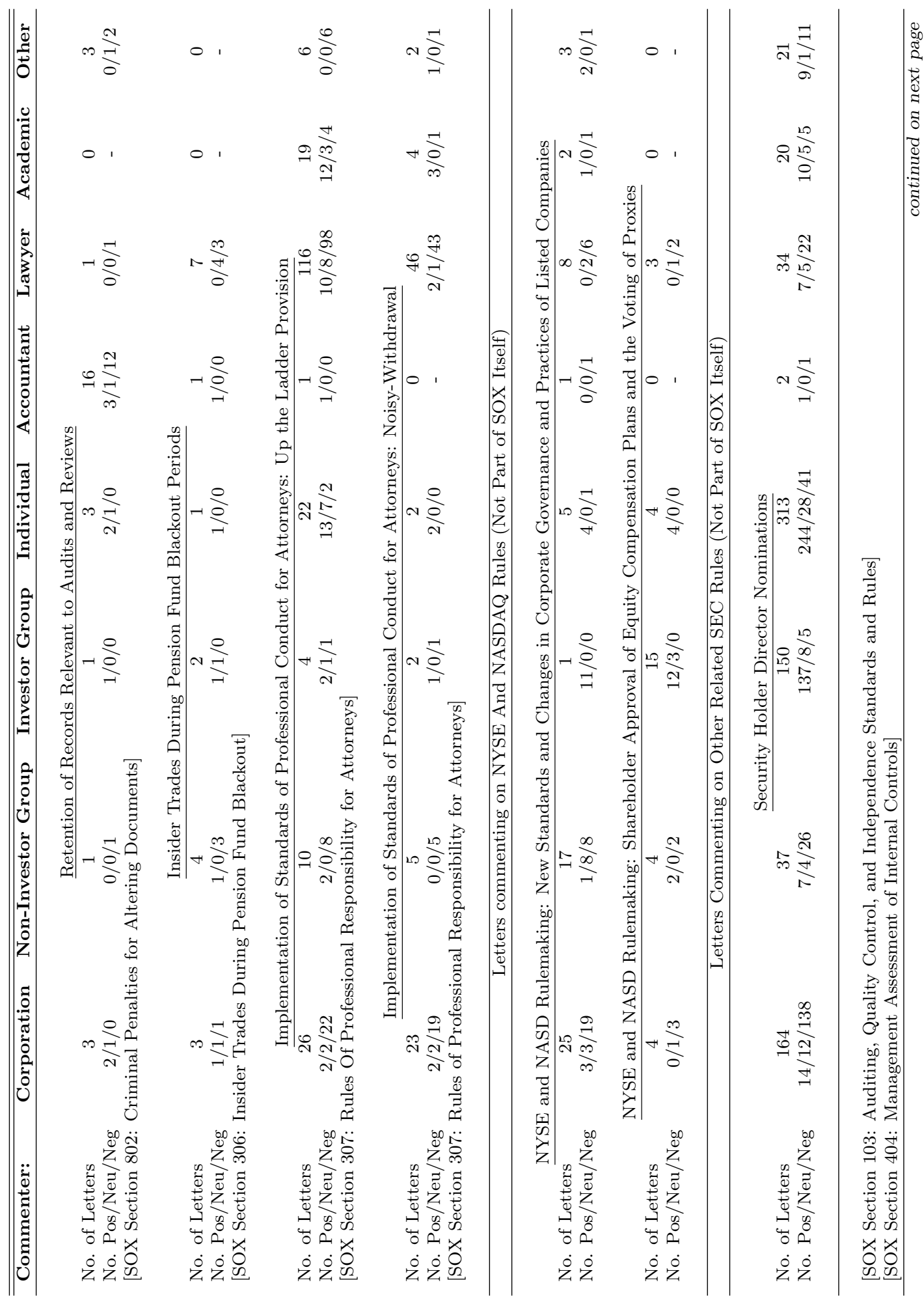




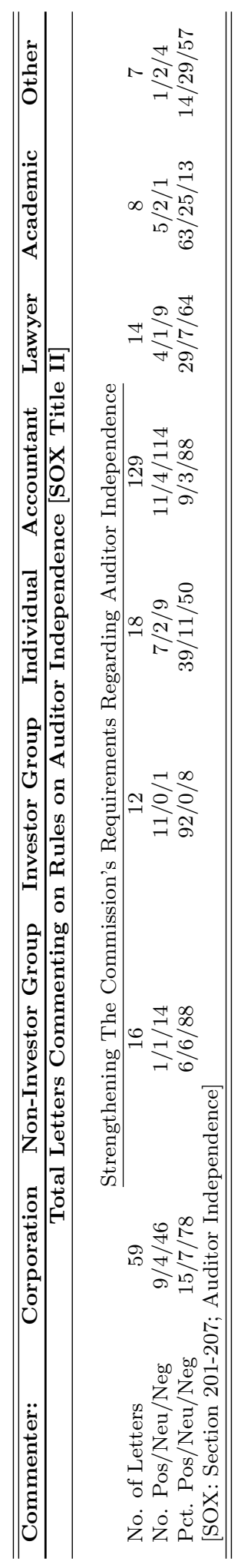




\section{Table II:}

\section{Characteristics of Publicly Traded Firms that Did and Did not Lobby the SEC}

This table presents firm characteristics for companies who did and did not lobby against the proposed SOX-related SEC

rule releases. Panel A examines the characteristics of both lobbying and non-lobbying companies with regards to the rules on Enhanced Financial Disclosure and the PCAOB proposed and implemented by the SEC. Panel B examines the characteristics of both lobbying and non-lobbying companies with regards to the corporate responsibility rules proposed and implemented by the SEC. Panel C examines the characteristics of both lobbying and non-lobbying companies with regards to Auditor Independence rules proposed and implemented by the SEC. We present the mean, standard deviation and the p-value for a t-test for no differences in means between lobbyers and non-lobbyers. Firm market capitalization is expressed in MM $\$$ and calculated for the end of week 6 of 2002 (Friday, February 8th). Book-to-market equity is calculated using book equity for the fiscal year ending in 2001 and market equity for the end of week 6 of 2002; this variable is winsorized at the top 2 and bottom 2 percentiles. Total assets (COMPUSTAT item 6) is expressed in MM \$ and is calculated in year 2001. Number of years the firm has been public is the number of years the firm has been publicly traded as of 2002; we cap this variable at 30 , because firms traded in NASDAQ are covered in CRSP only since 1972. Net Income (COMPUSTAT item 172) over sales (COMPUSTAT item 12 ) is calculated as of year 2000; we use 2000 (as opposed to 2001) since 2001 income may only be disclosed in early 2002 and could thus directly affect returns; this variable is winsorized at the top 2 and bottom 2 percentiles. Governance Index is the firm's Gompers, Ishii and Metrick (2003) index calculated in year 2000. PAC is an indicator variable equal to one if the firm has a Political Action Committee that was registered with the Federal Election Commission's during the 1999-2000 period. Past Lobbying on Compensation Rules is an indicator variable equal to one if the firm has lobbied against the 1992 revision of executive compensation disclosure rules adopted by the SEC (See Lo, 2003). Past Lobbying on Proxy Rules is an indicator variable equal to one if the firm has lobbied against the new rules on proxy fights adopted by the SEC in 1992 (See Lo, 2003). Fraction of shares outstanding owned by institutions is calculated for the year 2001 based on Thompson Financial's CDA/Spectrum Institutional (13f) Holdings. Number of business segments is calculated using the COMPUSTAT Segments data for year 2001. Number of geographical segments is calculated using the COMPUSTAT Segments data for year 2001. Fraction of shares outstanding owned by executives is calculated including all the shared owned by the executives (generally the top 5) included in Execucomp for year 2001. Audit fees are expressed in MM \$ and calculated in year 2001. Finally, the table reports the summary statistics for Standard Industrial Classification code (indicator variables). 


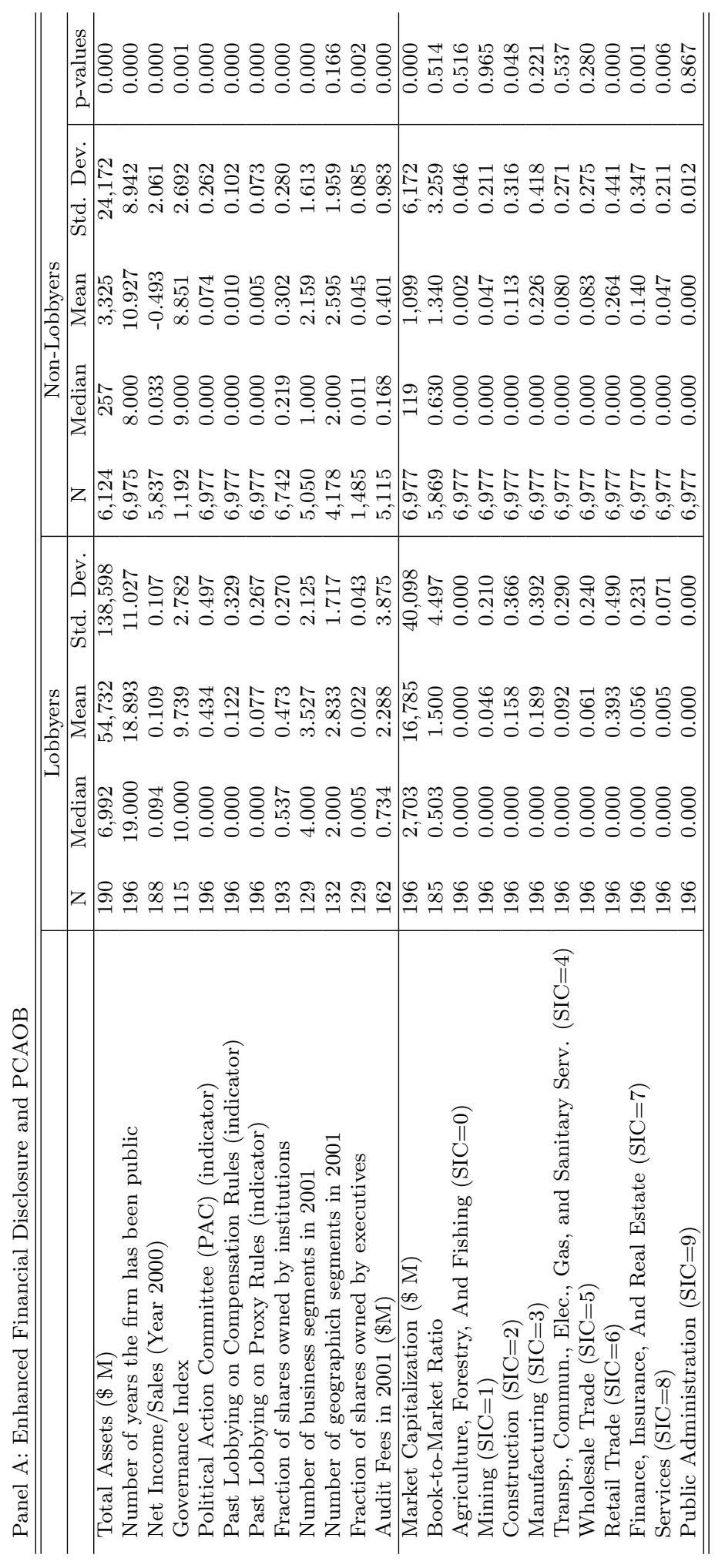




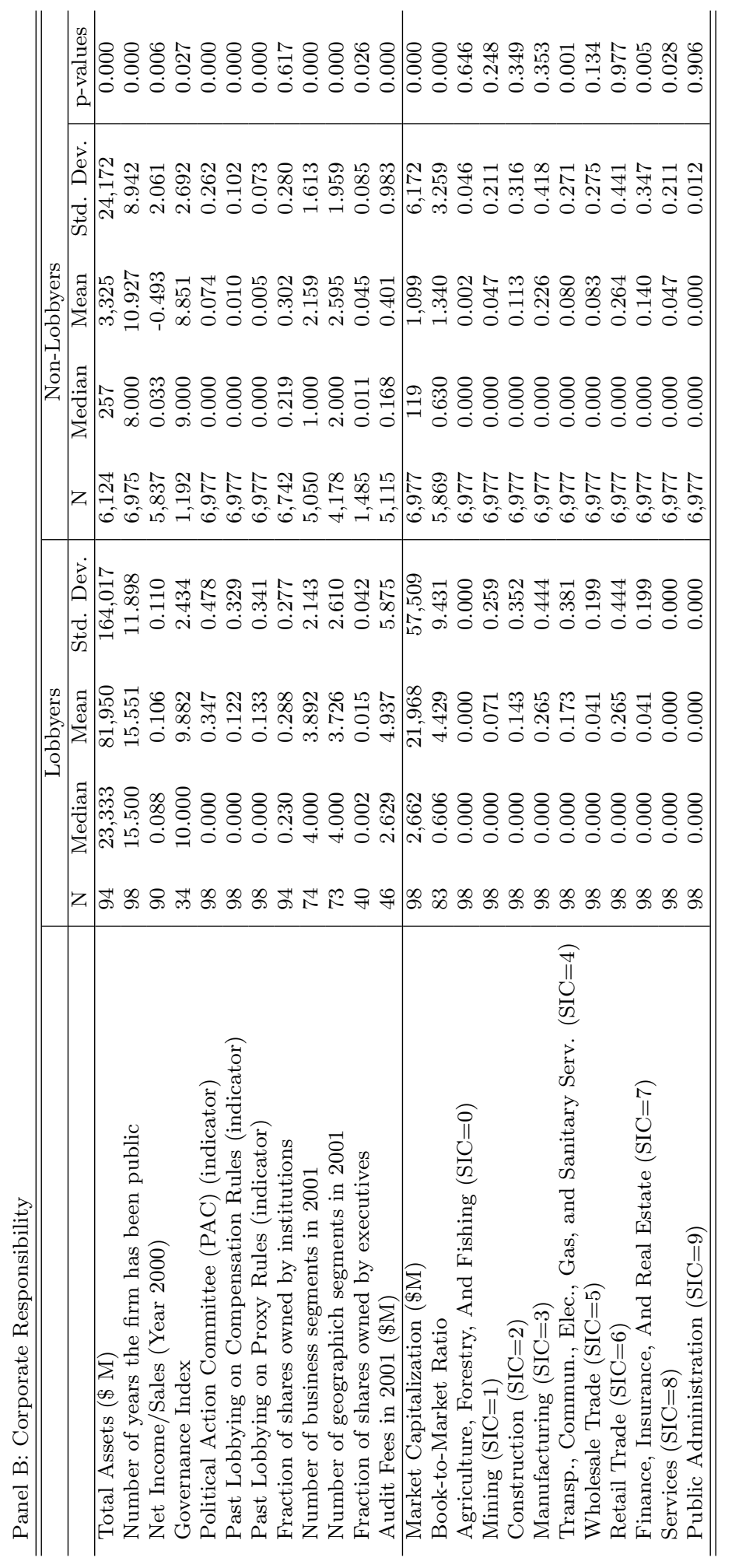




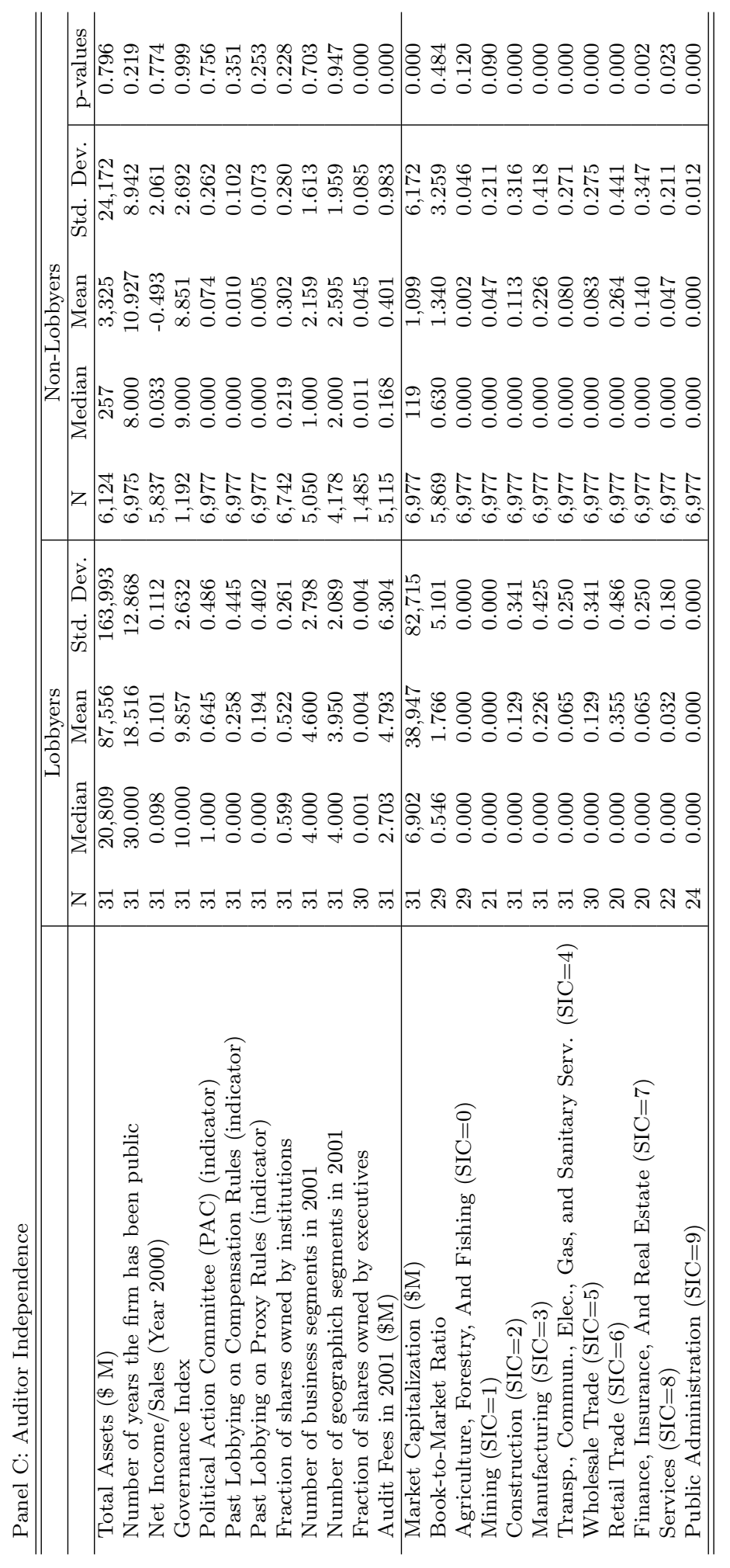




\section{Table III:}

\section{Predictability of Lobbying by Corporate Insiders}

The table presents the results of probit analysis of the likelihood of a company lobbying against SOX-related SEC rule releases. In columns (1),(2), and (3) the dependent variable is an indicator taking the value of one if the firm lobbied against one or more of the rules on Enhanced Financial Disclosure and PCAOB proposed and implemented by the SEC, and zero otherwise. In columns (4),(5), and (6) the dependent variable is an indicator taking the value of one if the firm lobbied against one or more of the rules on Corporate Responsibility proposed and implemented by the SEC, and zero otherwise. In columns (7), (8), and (9) the dependent variable is an indicator taking the value of one if the firm lobbied against one or more of the rules Auditors Independence proposed and implemented by the SEC, and zero otherwise. In Log of Market Capitalization is calculated at the end of week 6 of 2002 (Friday, February 8th). Book-to-Market Ratio is calculated using book equity for the fiscal year ending in 2001 and market equity for the end of week 6 of 2002 (Friday, February 8th). Total assets (COMPUSTAT item 6) is expressed in MM $\$$ and it is calculated at the end of 2001. Number of years the firm has been public is the number of years the firm has been publicly traded as of 2002; we cap this variable at 30, because firms traded in NASDAQ are covered in CRSP only since 1972. Net Income (COMPUSTAT item 172) over sales (COMPUSTAT item 12) is calculated as of year 2000; we use 2000 (as opposed to 2001) since 2001 income may only be disclosed in early 2002 and could thus directly affect returns; this variable is winsorized at the top 2 and bottom 2 percentiles. Governance Index is the firm's Gompers, Ishii and Metrick (2003) index calculated in year 2000 (Higher values of the governance index indicate more entrenched management and lower shareholder power). PAC is an indicator variable equal to one if the firm has a Political Action Committee that was registered with the Federal Election Commission's during the 1999-2000 period; Past Lobbying on Compensation Rules is an indicator variable equal to one if the firm has lobbied against the 1992 revision of executive compensation disclosure rules adopted by the SEC (see Lo, 2003). Past Lobbying on Proxy Rules is an indicator variable equal to one if the firm has lobbied against the new rules on proxy fights adopted by the SEC in 1992 (see Lo, 2003). Fraction of shares outstanding owned by institutions is calculated in year 2001 using Thompson Financial's CDA/Spectrum Institutional (13f) Holdings. Number of business segments is calculated using the COMPUSTAT Segments data for year 2001. Number of geographical segments is calculated using the COMPUSTAT Segments data for year 2001. Fraction of shares outstanding owned by executives is calculated including all the shared owned by the executives (generally the top 5) included in Execucomp for year 2001. The logarithm of the firm's audit fees (expressed in MM \$) is calculated in year 2001. Finally, all the regressions include indicator variables for Standard Industrial Classification code. All tests use White (1980) heteroscedasticity-consistent robust standard errors. 


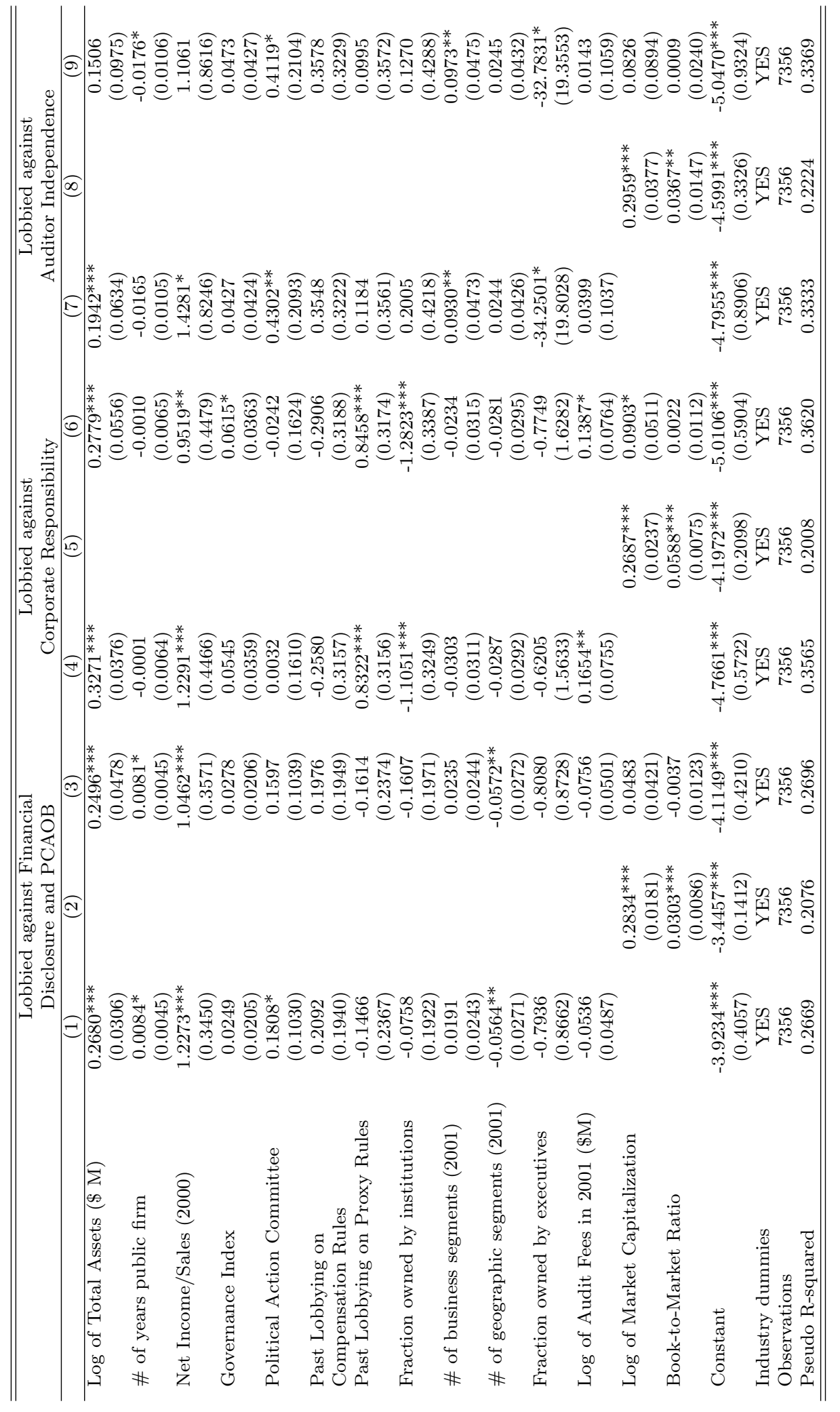




\section{Table IV:}

\section{Portfolio Analysis: Abnormal Excess Returns During Period Leading Up to Passage of the Sarbanes-Oxley Act of 2002 and the Period from Passage to the End of 2004}

The table presents the abnormal excess returns for firms that lobbied against SOX related rules relative to non-lobbying firms. Panel A reports results for weekly excess returns averaged across lobbying firms. Panel B reports results for weekly excess returns averaged across firms that are predicted to lobby based on the results of Table III. The first section of the tables presents the results for firms that lobbied against enhanced financial disclosure and PCAOB rules; the second section of the tables presents the results for firms that lobbied against corporate responsibility rules; the third section of the tables presents the results for firms that lobbied against auditor independence rules. Excess returns are calculated for each lobbying firm by subtracting the return on a portfolio of non-lobbying firms of similar size (columns (1)-(3)) or of similar size and book-to-market equity (columns (4)-(6)) or of similar size and in the same 1-digit industry category (columns (7)-(9)). Excess returns are then averaged for each week across the set of lobbying firms. These average excess returns are then regressed either just on a constant or on a constant and the three market, size and book-to-market factors. This is done first for the 24-week period from week 7 to 30 of 2002 leading up to passage of SOX only (columns (1), (4) and (7)) and then for the period starting with week 7 of 2002 and ending in the last week of 2004 (columns (2)-(3), (5)-(6), and (8)-(9)) with different constant terms allowed for the lead-up period and for the post-SOX period. 
Panel A: Lobbyers versus Non-Lobbyers

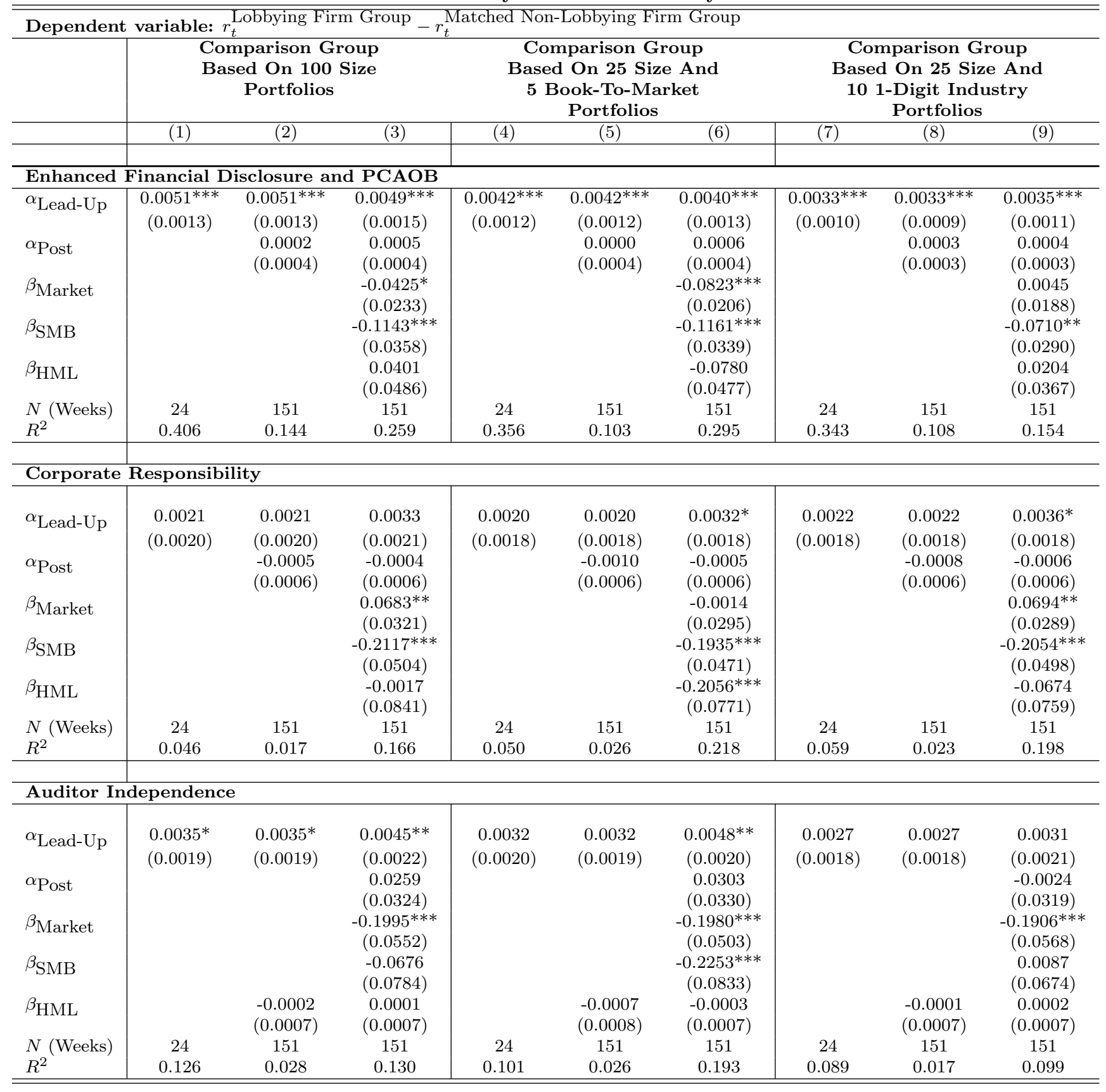


Panel B: Firms Predicted to Lobby versus Non-Lobbyers

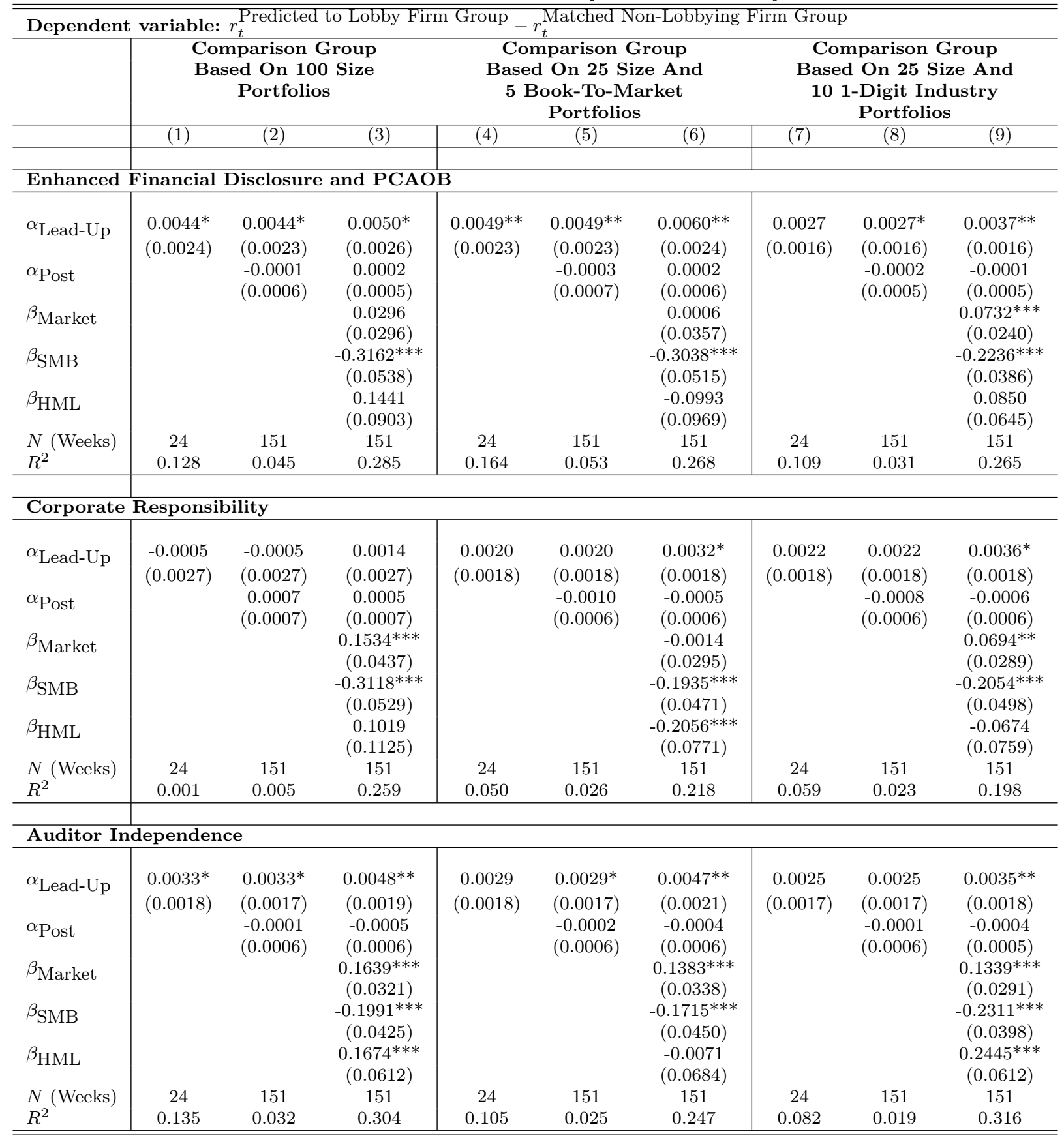


Table V:

\section{Firm Level Analysis: \\ Abnormal Excess Returns During Period Leading Up to Passage of the Sarbanes-Oxley Act of 2002 and the Period from Passage to the End of 2004}

This table reports results for the excess returns at the firm level. In the first three columns the dependent variable is the sum of each firm's excess return minus the riskless rate during the lead-up period, while in the last three columns it is the sum of each firm's excess return minus the riskless rate during the post-SOX period. In Panel A Lobbied Against Enhanced Financial Disclosure and PCAOB Rules is an indicator variable equal to one if the firm lobbied against the SEC rules related to SOX Section IV; Lobbied Against Corporate Responsibility Rules is an indicator variable equal to one if the firm lobbied against the SEC rules related to SOX Section III; Lobbied Against Auditors Independence Rules is an indicator variable equal to one if the firm lobbied against the SEC rules related to SOX Section IV. In Panel B Predicted to Lobby Against Enhanced Financial Disclosure and PCAOB Rules is an indicator variable equal to one if the firm was predicted to lobby against the SEC rules related to SOX Section IV, based on our probit model of Table III; Predicted to Lobby Against Corporate Responsibility Rules is an indicator variable equal to one if the firm was predicted to lobby against the SEC rules related to SOX Section III, based on our probit model; Predicted to Lobby Against Auditors Independence Rules is an indicator variable equal to one if the firm was predicted to lobby against the SEC rules related to SOX Section IV by our probit analysis. Dummies for size (100 Size dummies) are indicator variables for each size portfolio. Dummies for size and book to market are indicator variables for 25 size portfolios and 5 book-to-market categories. Since the firms in our sample are very large, we defined the cutoff for size to include enough observations in each group (the size ranges are 7 percentiles wide up to the 70 th percentile, and then 2 percentiles wide). Dummies for size and industry are indicator variables for 25 size portfolios and 10 industry classifications. To create these indicators we defined the cutoff for size to include enough observations in each group (the size ranges are 7 percentiles wide up to the 70 th percentile, and then 2 percentiles wide).

Panel A:

\begin{tabular}{|c|c|c|c|c|c|c|}
\hline & \multicolumn{3}{|c|}{$\begin{array}{l}\text { Cumulative weekly excess } \\
\text { return minus the riskless rate } \\
\text { during the leadup period }\end{array}$} & \multicolumn{3}{|c|}{$\begin{array}{l}\text { Cumulative weekly excess } \\
\text { return minus the riskless rate } \\
\text { during the post period }\end{array}$} \\
\hline $\begin{array}{l}\text { Lobbied Against Enhanced Finan- } \\
\text { cial Disclosure and PCAOB Rules }\end{array}$ & $\begin{array}{c}(1) \\
0.1315^{* * *} \\
(0.0353)\end{array}$ & $\begin{array}{c}(2) \\
0.1070^{* * *} \\
(0.0369)\end{array}$ & $\begin{array}{c}(3) \\
0.0864^{* *} \\
(0.0347)\end{array}$ & $\begin{array}{c}(4) \\
0.0401 \\
(0.0649)\end{array}$ & $\begin{array}{c}(5) \\
0.0248 \\
(0.0690)\end{array}$ & $\begin{array}{c}(6) \\
0.0567 \\
(0.0649)\end{array}$ \\
\hline $\begin{array}{l}\text { Lobbied Against Corporate } \\
\text { Responsibility Rules }\end{array}$ & $\begin{array}{c}0.0048 \\
(0.0481)\end{array}$ & $\begin{array}{c}0.0002 \\
(0.0511)\end{array}$ & $\begin{array}{c}0.0104 \\
(0.0471)\end{array}$ & $\begin{array}{l}-0.0594 \\
(0.0880)\end{array}$ & $\begin{array}{l}-0.0478 \\
(0.1003)\end{array}$ & $\begin{array}{l}-0.0798 \\
(0.0882)\end{array}$ \\
\hline $\begin{array}{l}\text { Lobbied Against Auditor } \\
\text { Independence Rules }\end{array}$ & $\begin{array}{c}0.0401 \\
(0.0834)\end{array}$ & $\begin{array}{c}0.0364 \\
(0.0877)\end{array}$ & $\begin{array}{c}0.0330 \\
(0.0817)\end{array}$ & $\begin{array}{l}-0.0356 \\
(0.1533)\end{array}$ & $\begin{array}{l}-0.0391 \\
(0.1652)\end{array}$ & $\begin{array}{l}-0.0096 \\
(0.1532)\end{array}$ \\
\hline $\begin{array}{l}\text { Dummies for size (100 Size dummies) } \\
\text { Dummies for size and book to market } \\
\text { Dummies for size and industry } \\
\text { Observations } \\
\text { R-squared }\end{array}$ & $\begin{array}{c}-0.1560^{* * *} \\
(0.0054) \\
\text { YES } \\
\text { NO } \\
\text { NO } \\
7250 \\
0.032\end{array}$ & $\begin{array}{c}-0.1634^{* * *} \\
(0.0058) \\
\text { NO } \\
\text { YES } \\
\text { NO } \\
6381 \\
0.076\end{array}$ & $\begin{array}{c}-0.1549 * * * \\
(0.0052) \\
\mathrm{NO} \\
\mathrm{NO} \\
\mathrm{YES} \\
7250 \\
0.112\end{array}$ & $\begin{array}{c}0.7557^{* * *} \\
(0.0101) \\
\text { YES } \\
\text { NO } \\
\text { NO } \\
6913 \\
0.057\end{array}$ & $\begin{array}{c}0.7991^{* * *} \\
(0.0112) \\
\text { NO } \\
\text { YES } \\
\text { NO } \\
5914 \\
0.067\end{array}$ & $\begin{array}{c}0.7554^{* * *} \\
(0.0100) \\
\text { NO } \\
\text { NO } \\
\text { YES } \\
6913 \\
0.096\end{array}$ \\
\hline
\end{tabular}


Panel B:

\begin{tabular}{|c|c|c|c|c|c|c|}
\hline \multirow[b]{2}{*}{$\begin{array}{l}\text { Predicted to Lobby Against Enhanced Finan- } \\
\text { cial Disclosure and PCAOB Rules }\end{array}$} & \multicolumn{3}{|c|}{$\begin{array}{l}\text { Cumulative weekly excess } \\
\text { return minus the riskless rate } \\
\text { during the leadup period }\end{array}$} & \multicolumn{3}{|c|}{$\begin{array}{l}\text { Cumulative weekly excess } \\
\text { return minus the riskless rate } \\
\text { during the post period }\end{array}$} \\
\hline & $\begin{array}{c}(1) \\
0.1258^{* * *} \\
(0.0468)\end{array}$ & $\begin{array}{c}(2) \\
0.1215^{* *} \\
(0.0483)\end{array}$ & $\begin{array}{c}(3) \\
0.0623 \\
(0.0486)\end{array}$ & $\begin{array}{c}(4) \\
-0.0513 \\
(0.0874)\end{array}$ & $\begin{array}{c}(5) \\
-0.0629 \\
(0.0932)\end{array}$ & $\begin{array}{c}(6) \\
-0.0195 \\
(0.0921)\end{array}$ \\
\hline $\begin{array}{l}\text { Predicted to Lobby Against Corporate } \\
\text { Responsibility Rules }\end{array}$ & $\begin{array}{l}-0.0190 \\
(0.0362)\end{array}$ & $\begin{array}{l}-0.0114 \\
(0.0410)\end{array}$ & $\begin{array}{l}-0.0007 \\
(0.0359)\end{array}$ & $\begin{array}{c}0.0717 \\
(0.0663)\end{array}$ & $\begin{array}{c}0.0983 \\
(0.0821)\end{array}$ & $\begin{array}{c}0.0169 \\
(0.0670)\end{array}$ \\
\hline $\begin{array}{l}\text { Predicted to Lobby Against Auditor } \\
\text { Independence Rules }\end{array}$ & $\begin{array}{c}0.0626 \\
(0.0430)\end{array}$ & $\begin{array}{c}0.0542 \\
(0.0448)\end{array}$ & $\begin{array}{c}0.0419 \\
(0.0434)\end{array}$ & $\begin{array}{l}-0.0373 \\
(0.0805)\end{array}$ & $\begin{array}{l}-0.0672 \\
(0.0851)\end{array}$ & $\begin{array}{l}-0.0266 \\
(0.0830)\end{array}$ \\
\hline Constant & $\begin{array}{c}-0.1567^{* * *} \\
(0.0055)\end{array}$ & $\begin{array}{c}-0.1650^{* * *} \\
(0.0060)\end{array}$ & $\begin{array}{c}-0.1550^{* * *} \\
(0.0053)\end{array}$ & $\begin{array}{c}0.7562^{* * *} \\
(0.0103)\end{array}$ & $\begin{array}{c}0.8002^{* * *} \\
(0.0116)\end{array}$ & $\begin{array}{c}0.7566^{* * *} \\
(0.0102)\end{array}$ \\
\hline Dummies for size (100 Size dummies) & YES & NO & NO & YES & NO & NO \\
\hline Dummies for size and book to market & $\mathrm{NO}$ & YES & NO & NO & YES & NO \\
\hline Dummies for Size and Industry & $\mathrm{NO}$ & NO & YES & NO & NO & YES \\
\hline Observations & 7250 & 6381 & 7250 & 6913 & 5914 & 6913 \\
\hline R-squared & 0.031 & 0.076 & 0.112 & 0.057 & 0.067 & 0.096 \\
\hline
\end{tabular}




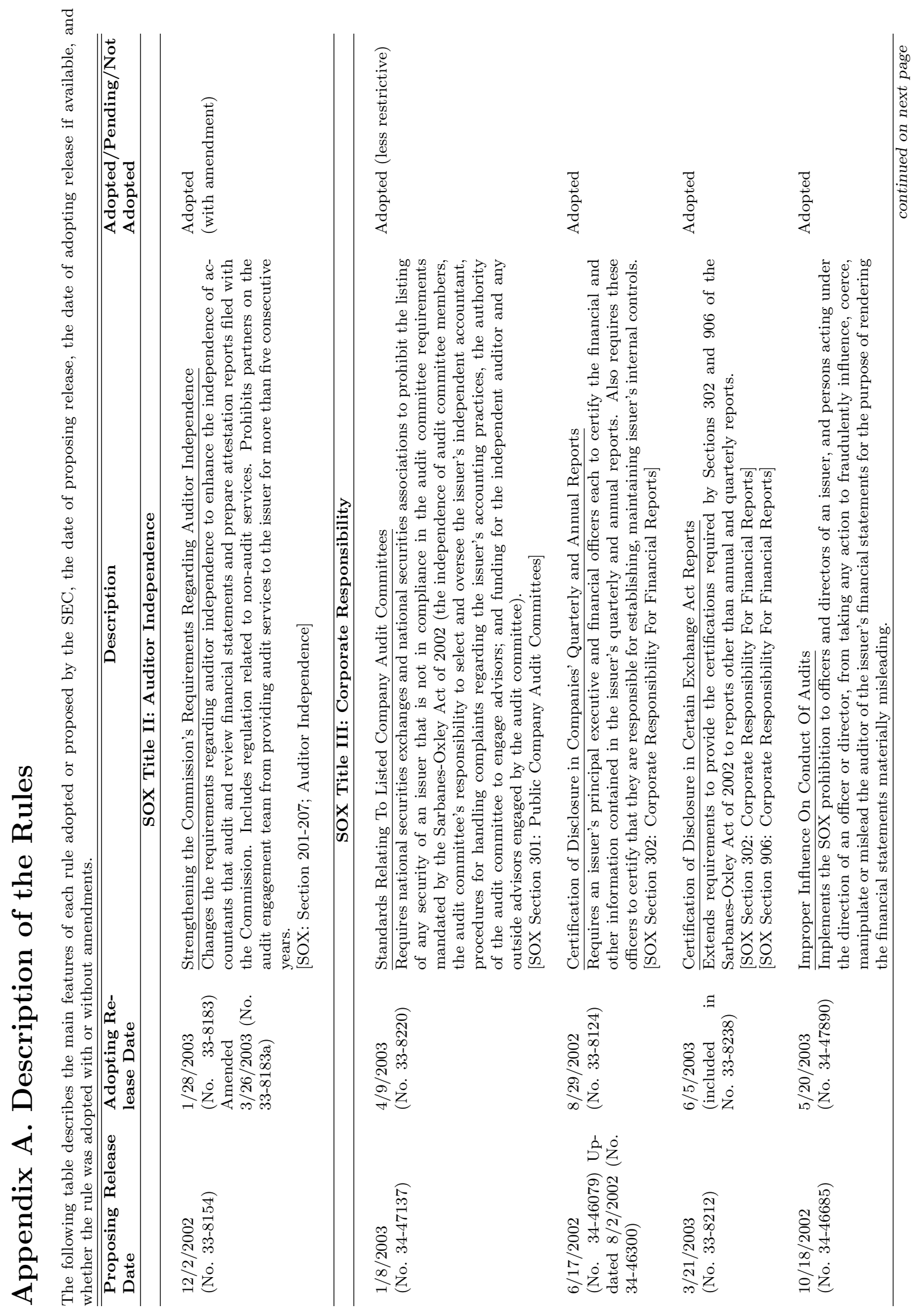




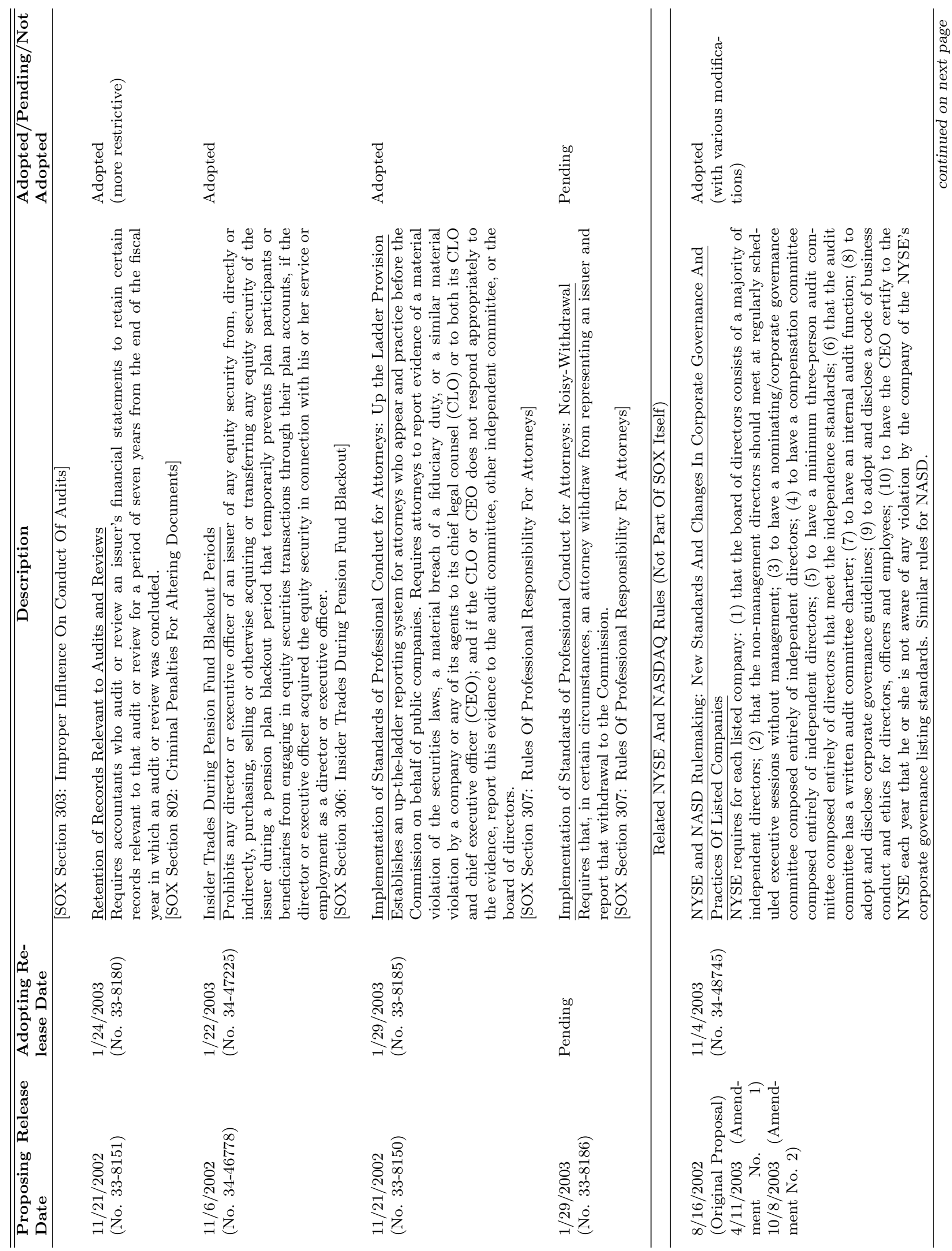




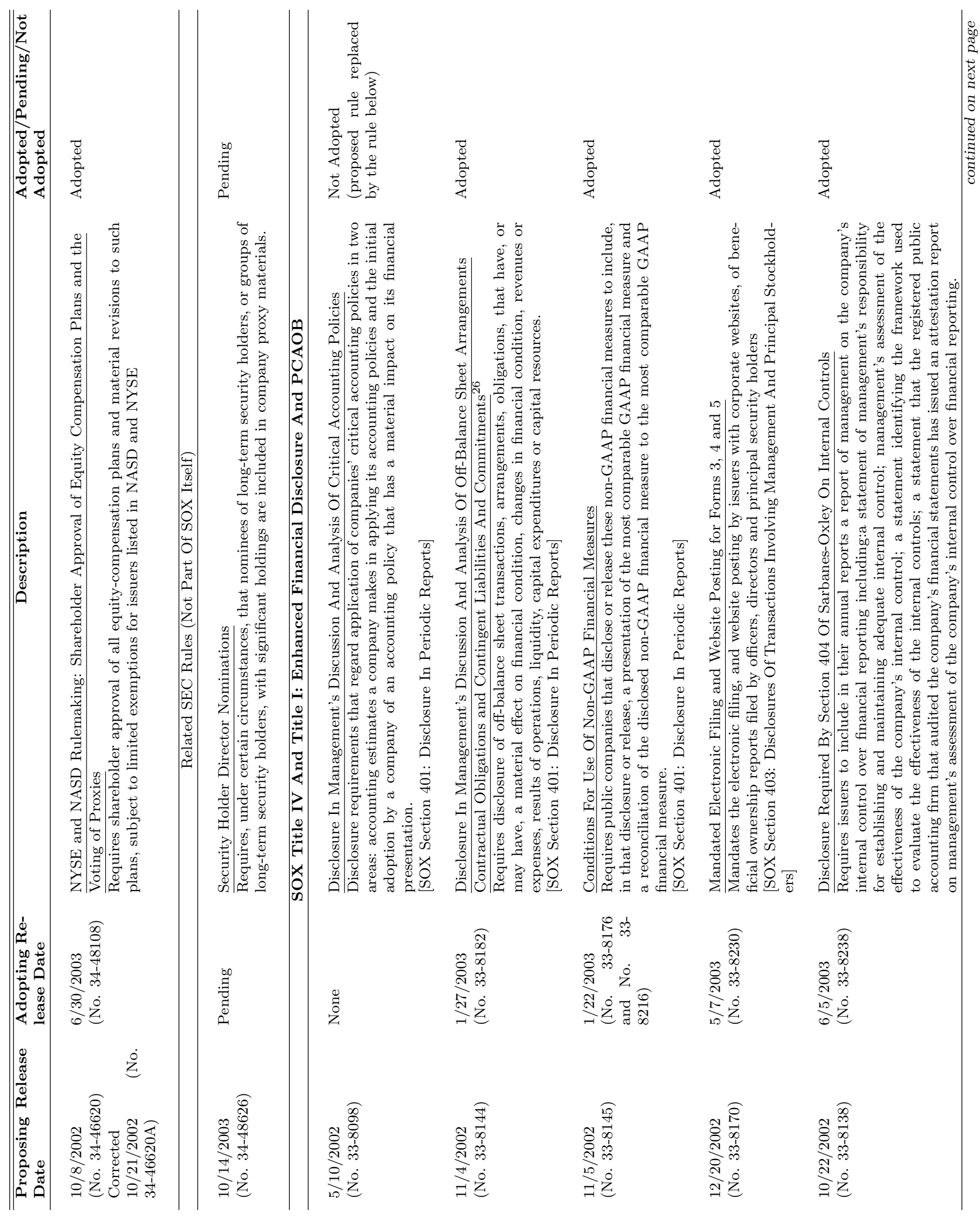




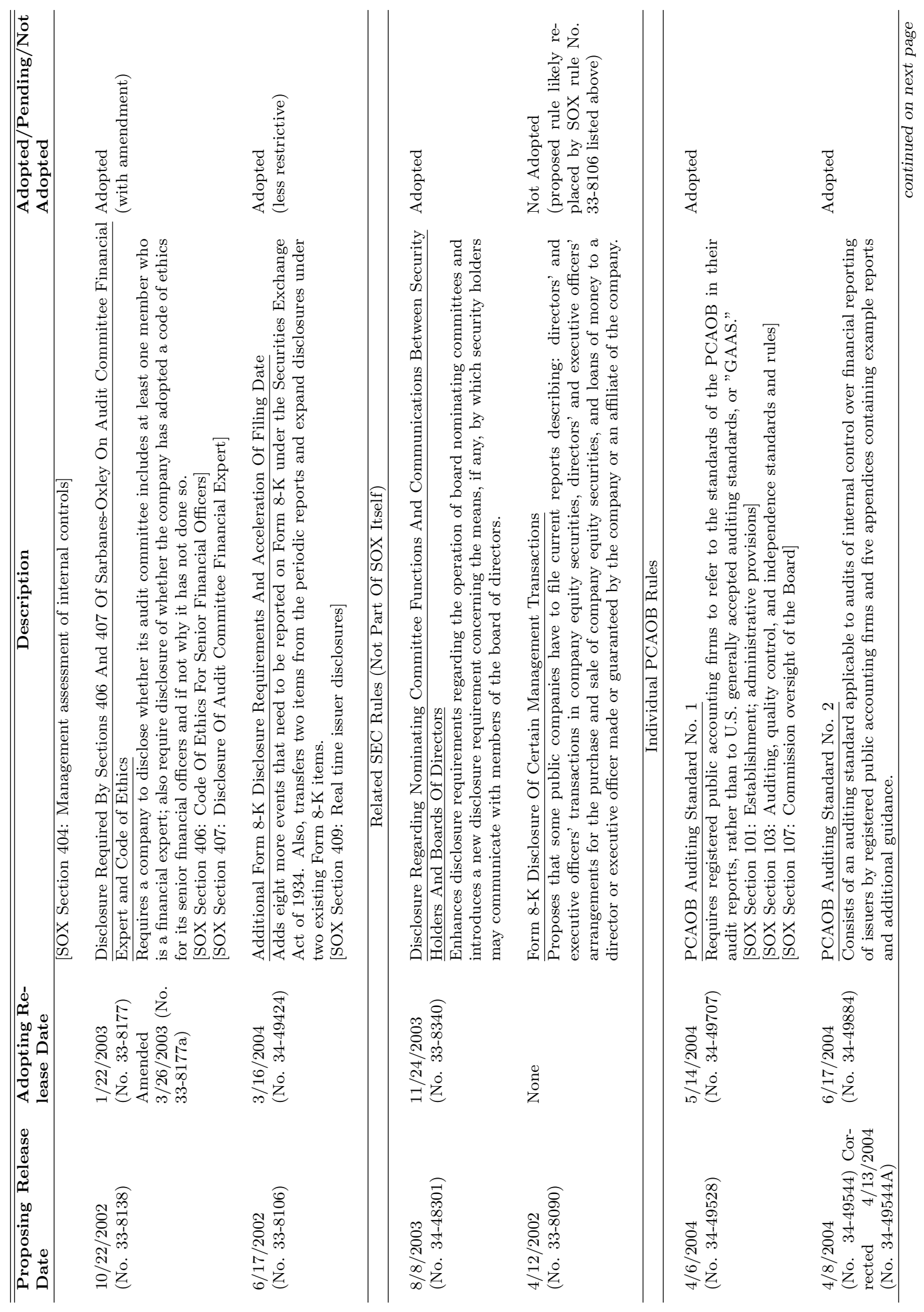




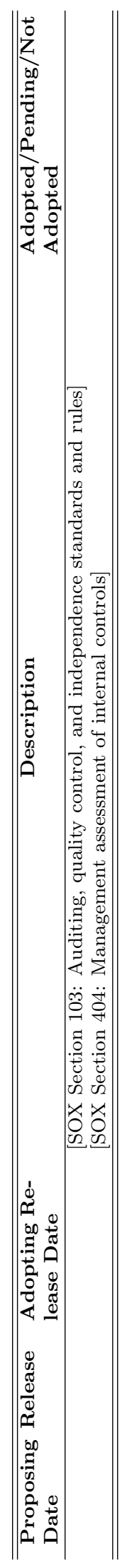




\section{Figure 1. Cumulative Excess Returns around Date of Filing Lobbying Letter with Negative Opinion}

The figures show the cumulative excess returns for companies who lobby the SEC around the date of SEC receipt of the lobbying letter. Results are shown separately for firms lobbying against one of the SOX enhanced disclosure rules, corporate responsibility rules, and auditor independence rules, and are based exclusively on letters expressing negative opinions about the particular rule. In each graph, results are shown for two different definitions of excess returns. The lines labelled "No factor adjustment" are based on excess returns defined as (return on lobbying firm stock)-(return on a size-matched comparison group). The lines labelled "With factor adjustment" are based on excess returns defined as the residual from a regression (run on weekly data from week 31 of 2002 to the end of 2004) of (return on lobbying firm stock)-(return on size-matched comparison group) on a constant, the excess return on the market, and Fama and French's the size and book-to-market factors SMB and HML. For each approach excess returns are averaged across lobbying firms for each week in event time, and then summed over time, starting 10 weeks before the week of the letter and ending 20 weeks after the week of the letter. Results are based only on letters filed at least 10 weeks after the passage of SOX on $7 / 30 / 2002$ so that no point in the figures overlap with the period leading up to passage of SOX. 


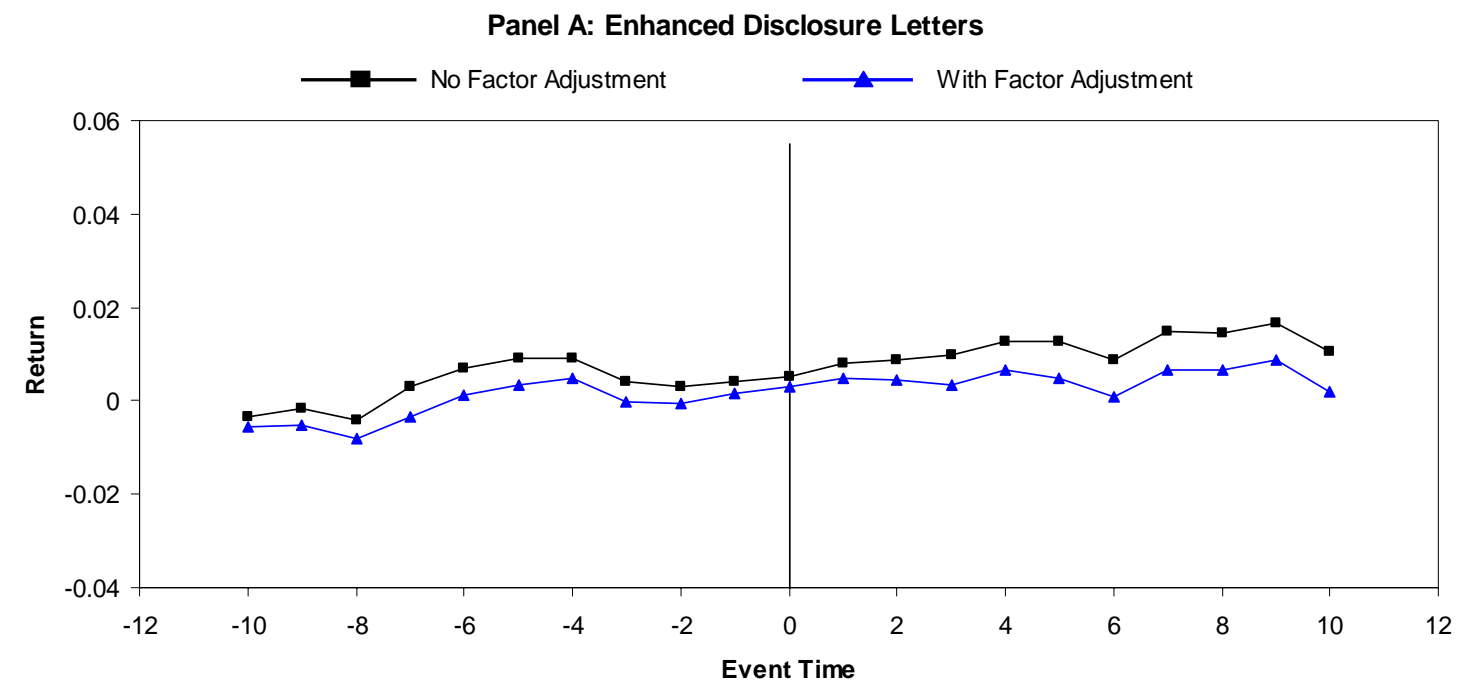

Panel B: Auditor Independence Letters

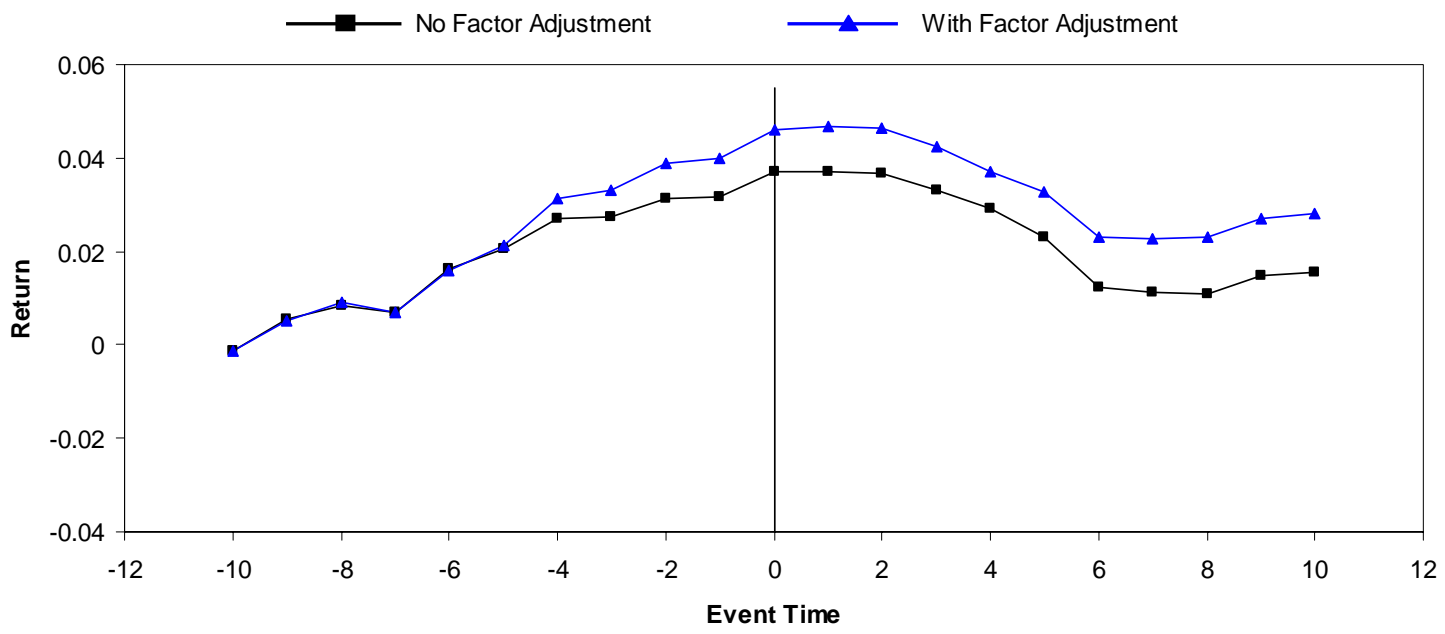

Panel C: Corporate Responsibility Letters

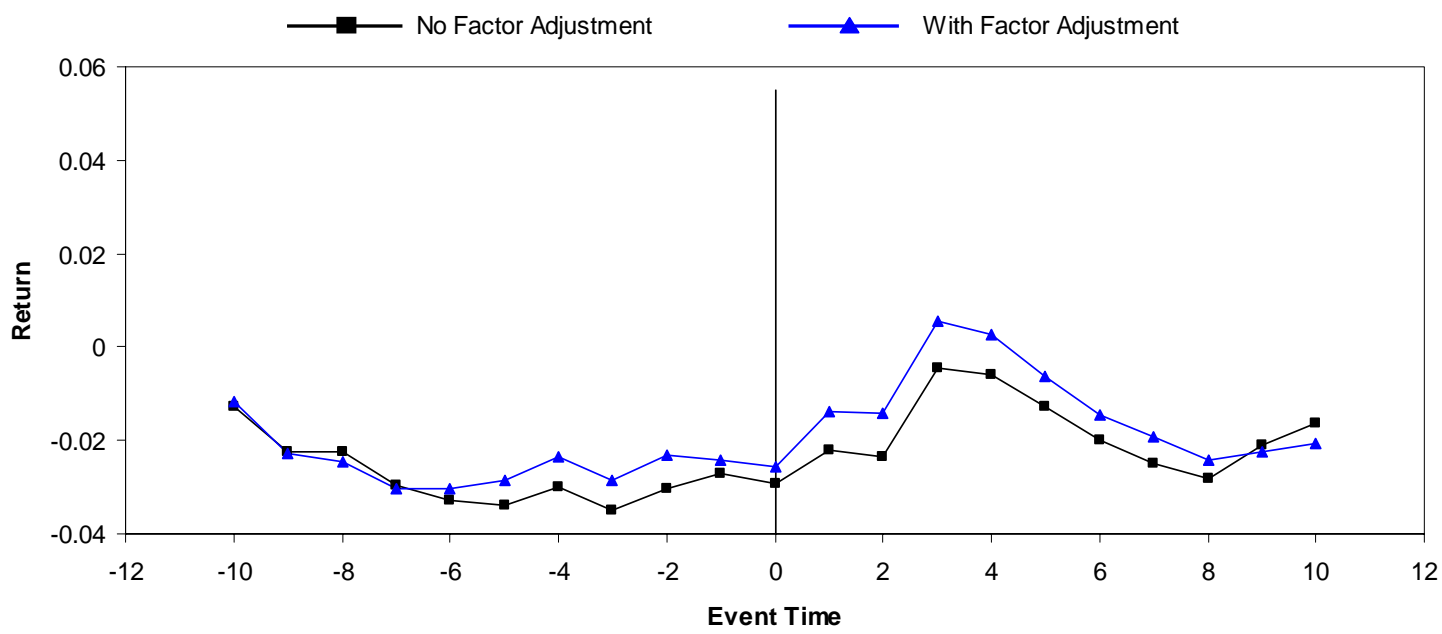




\section{Figure 2. Cumulative Excess Returns during Years 2002-2004 for Publicly Traded}

Firms that Lobbied the SEC

The figure shows the cumulative excess returns of firms lobbying firms against one or more of the 'Enhanced Disclosure' provisions of SOX over and above their matched comparison groups starting in week 7 of 2002 . Three sets of cumulative excess returns are shown. Panel A is based on a size-matched (100 size portfolios) control group of non-lobbying firms. Panel B is based on a size and book-to-market equity (25 size portfolios and 5 book-to-market portfolios) matched control group. Panel $\mathrm{C}$ is based on a size and industry-matched (25 size portfolios and 10 industry portfolios) control group. In each graph, two lines are shown. The unadjusted cumulative excess return is calculated by averaging the excess returns over the comparison group across lobbying firms in each week, and then summing these excess returns over time, starting in week 7 of year 2002. The factor-adjusted cumulative excess return is calculated by first regressing the excess return over the comparison group on the excess return on the market and the Fama-French size and book-to-market factors. The regression is run using weekly data from week 7 of 2002 until the end of 2004, and the alpha plus the residuals are averaged each week and then summed over time. The leftmost vertical lines indicates the beginning of serious negotiations about SOX in Congress while the rightmost vertical line indicates the week SOX was passed in Congress. 
Panel A: Comparison Group Based on 100 Size Portfolios

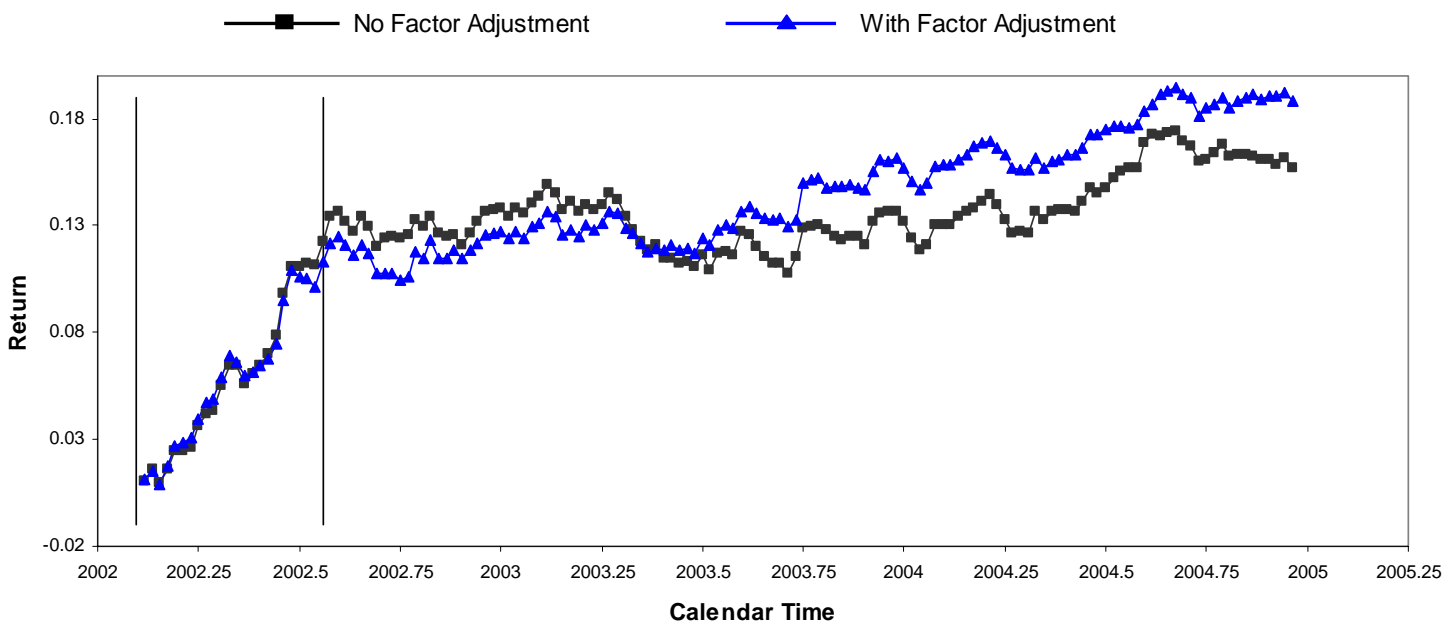

Panel B: Comparison Group Based on 25 Size and 5 Book-to-Market Portfolios

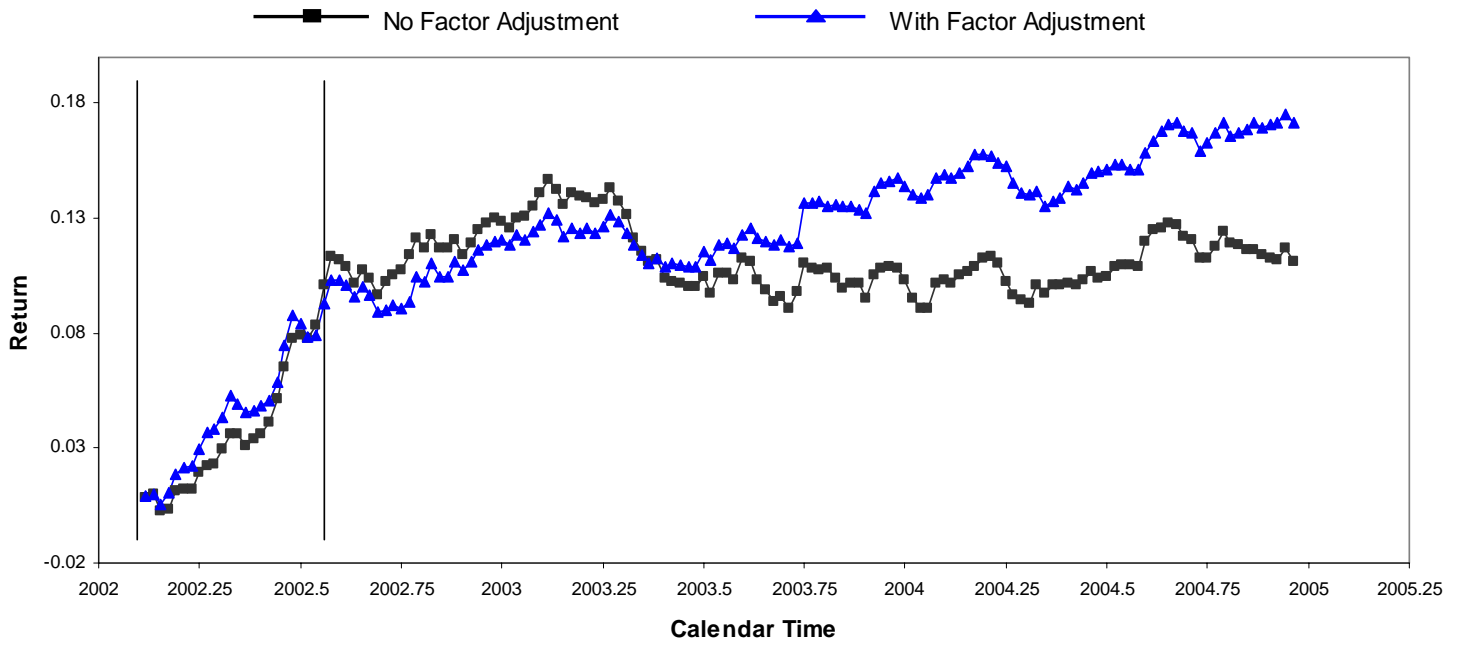

Panel C: Comparison Group Based on 25 Size and 10 1-Digit Industry Portfolios

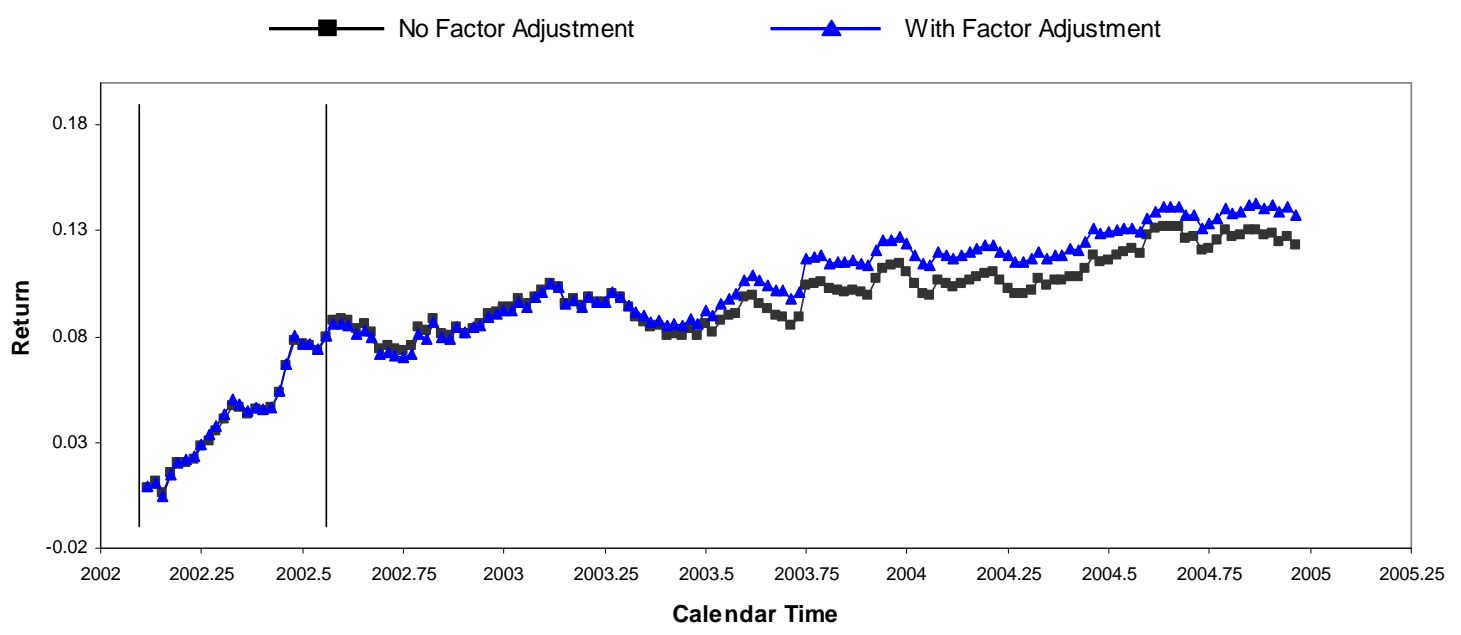




\section{Figure 3. Cumulative Excess Returns during Years 2002-2004 for Publicly Traded Firms that were Predicted to Lobby the SEC}

The figure shows the cumulative excess returns of firms that were predicted to lobby the SEC against one or more of the 'Enhanced Disclosure' provisions of SOX according to our models, over and above their matched comparison groups starting in week 7 of 2002. Predicted lobbyers are those firms whom our probit models place in the top $3 \%$ of firms based on likelihood of lobbying. Three sets of cumulative excess returns are shown. Panel A is based on a size-matched (100 size portfolios) control group of non-lobbying firms. Panel B is based on a size and book-to-market equity (25 size portfolios and 5 book-to-market portfolios) matched control group. Panel $\mathrm{C}$ is based on a size and industry-matched (25 size portfolios and 10 industry portfolios) control group. In each graph, two lines are shown. The unadjusted cumulative excess return is calculated by averaging the excess returns over the comparison group across predicted lobbying firms in each week, and then summing these excess returns over time, starting in week 7 of year 2002. The factor-adjusted cumulative excess return is calculated by first regressing the excess return over the comparison group on the excess return on the market and the Fama-French size and book-to-market factors. The regression is run using weekly data from week 7 of 2002 until the end of 2004, and the alpha plus the residuals are averaged each week and then summed over time. The leftmost vertical lines indicates the beginning of serious negotiations about SOX in Congress while the rightmost vertical line indicates the week SOX was passed in Congress. 
Panel A: Comparison Group Based on 100 Size Portfolios

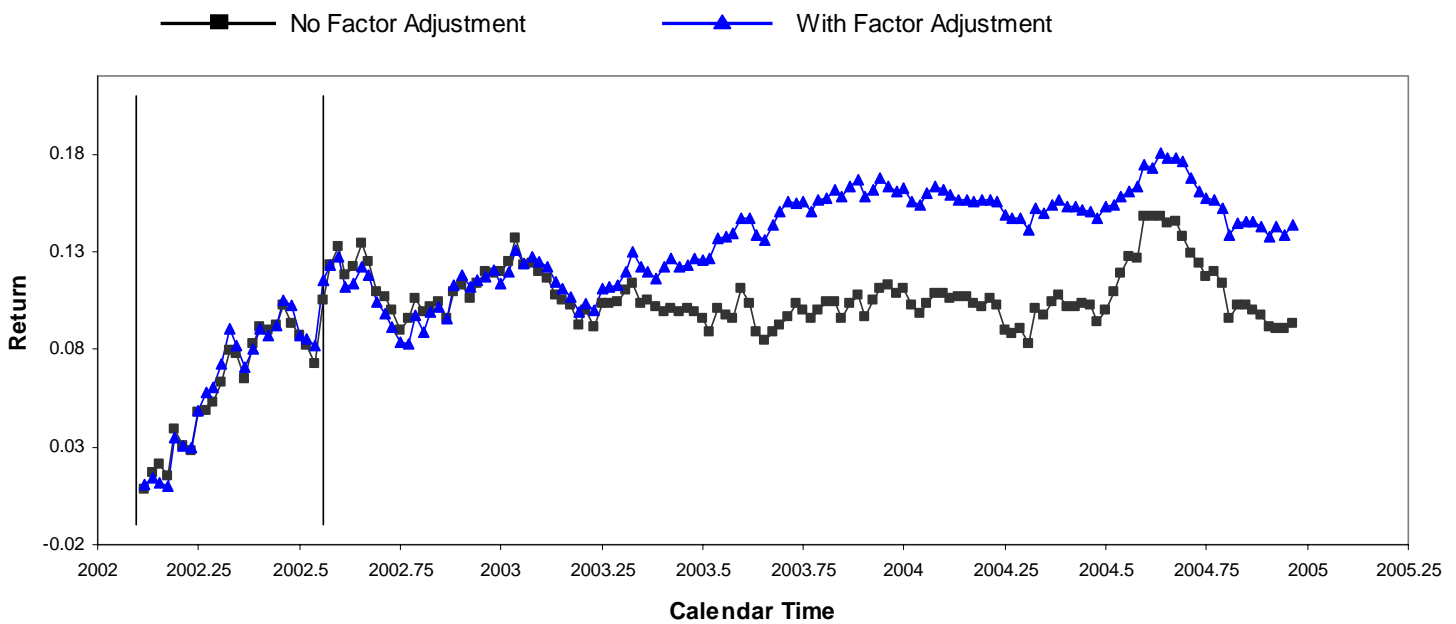

Panel B: Comparison Group Based on 25 Size and 5 Book-to-Market Portfolios

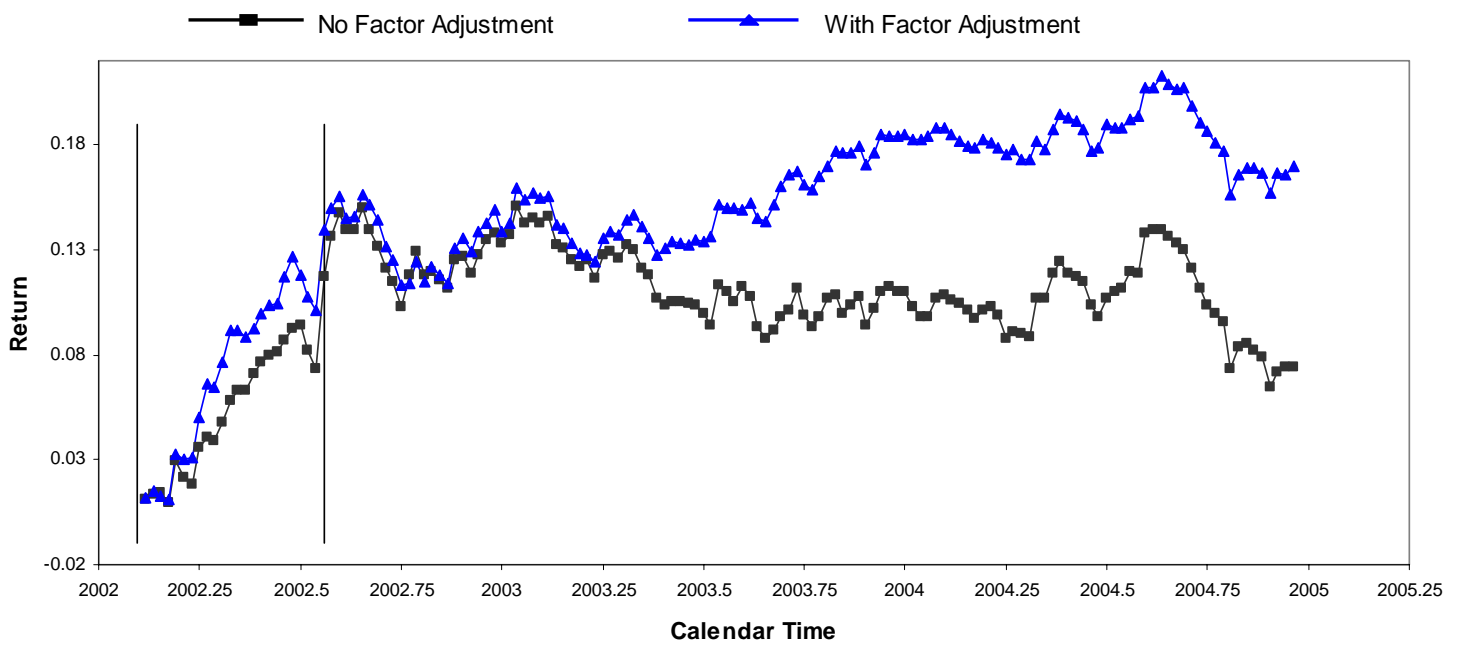

Panel C: Comparison Group Based on 25 Size and 10 1-Digit Industry Portfolios

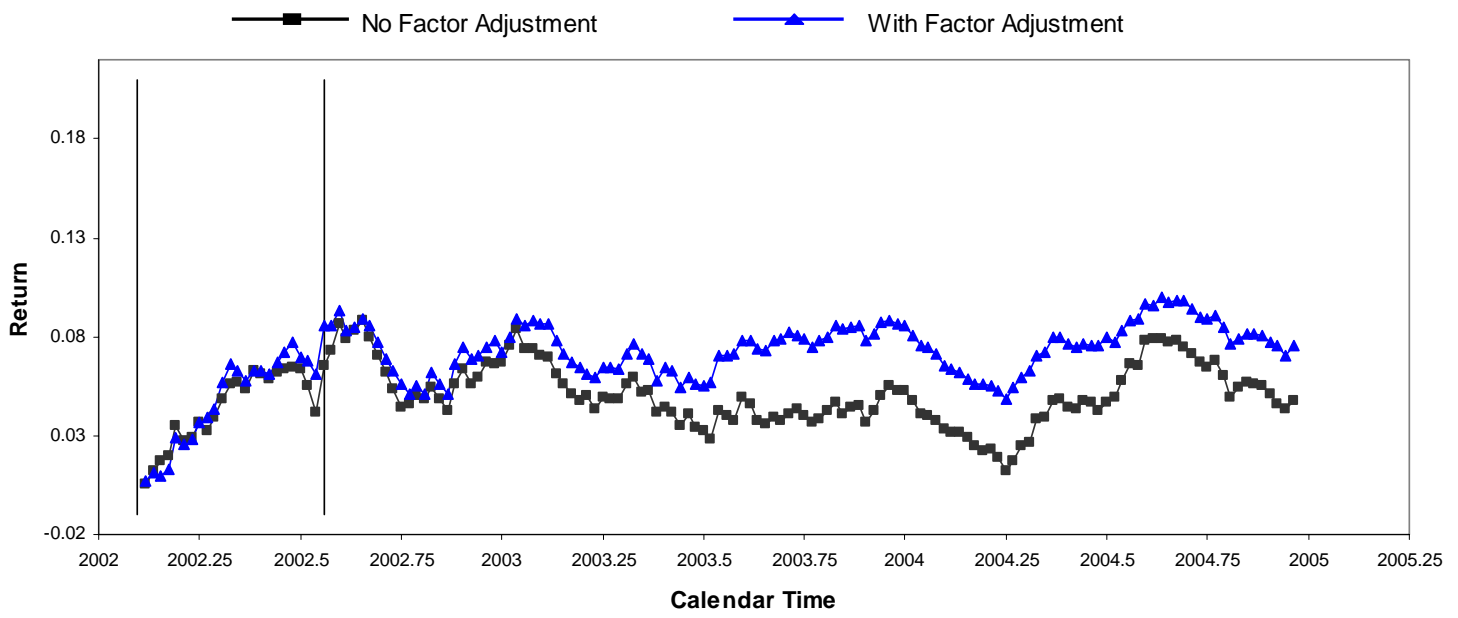




\section{Figure 4. Cumulative Excess Returns during Years 2002-2004 for Publicly Traded Firms that Lobbied the SEC (Section 404 Only)}

The figure shows the cumulative excess returns of firms lobbying firms against Section 404-related provisions of SOX over and above their matched comparison groups starting in week 7 of 2002 . Three sets of cumulative excess returns are shown. Panel A is based on a size-matched (100 size portfolios) control group of non-lobbying firms. Panel B is based on a size and book-to-market equity ( 25 size portfolios and 5 book-to-market portfolios) matched control group. Panel C is based on a size and industry-matched (25 size portfolios and 10 industry portfolios) control group. In each graph, two lines are shown. The unadjusted cumulative excess return is calculated by averaging the excess returns over the comparison group across lobbying firms in each week, and then summing these excess returns over time, starting in week 7 of year 2002 . The factor-adjusted cumulative excess return is calculated by first regressing the excess return over the comparison group on the excess return on the market and the Fama-French size and book-to-market factors. The regression is run using weekly data from week 7 of 2002 until the end of 2004, and the alpha plus the residuals are averaged each week and then summed over time. The leftmost vertical lines indicates the beginning of serious negotiations about SOX in Congress while the rightmost vertical line indicates the week SOX was passed in Congress. 
Panel A: Comparison Group Based on 100 Size Portfolios

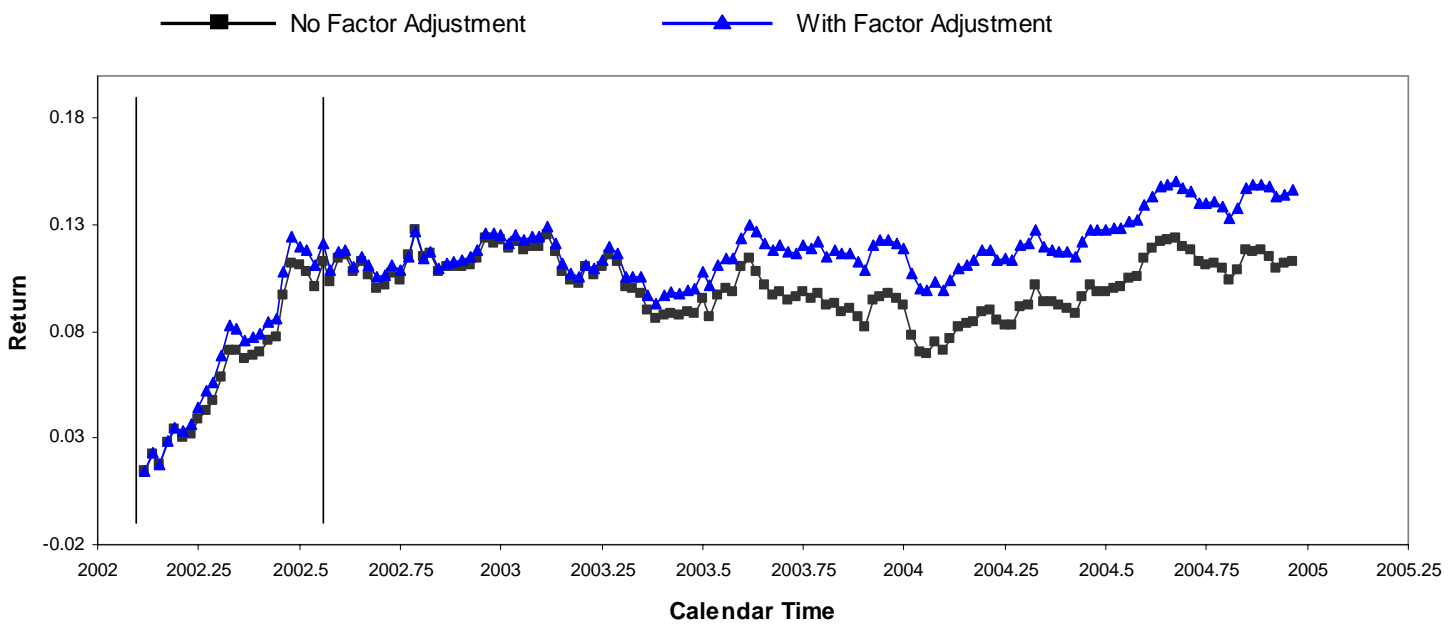

Panel B: Comparison Group Based on 25 Size and 5 Book-to-Market Portfolios

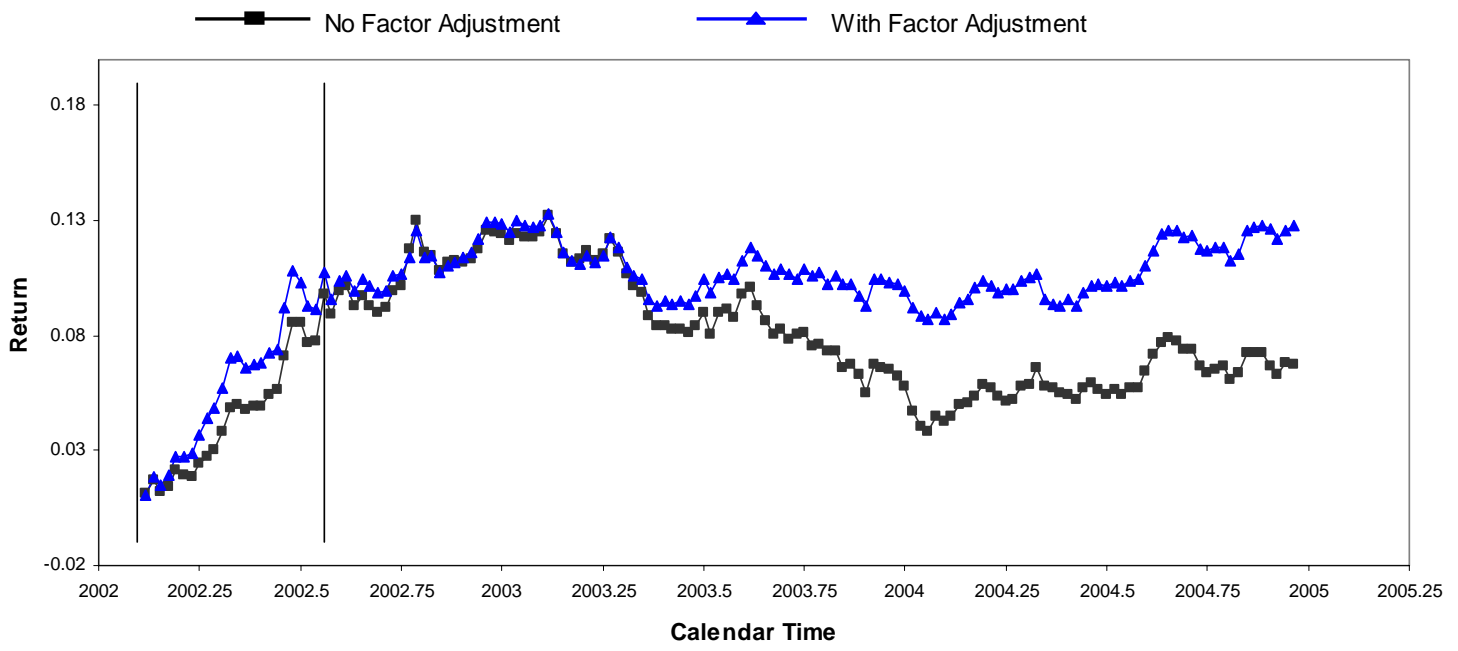

Panel C: Comparison Group Based on 25 Size and 10 1-Digit Industry Portfolios

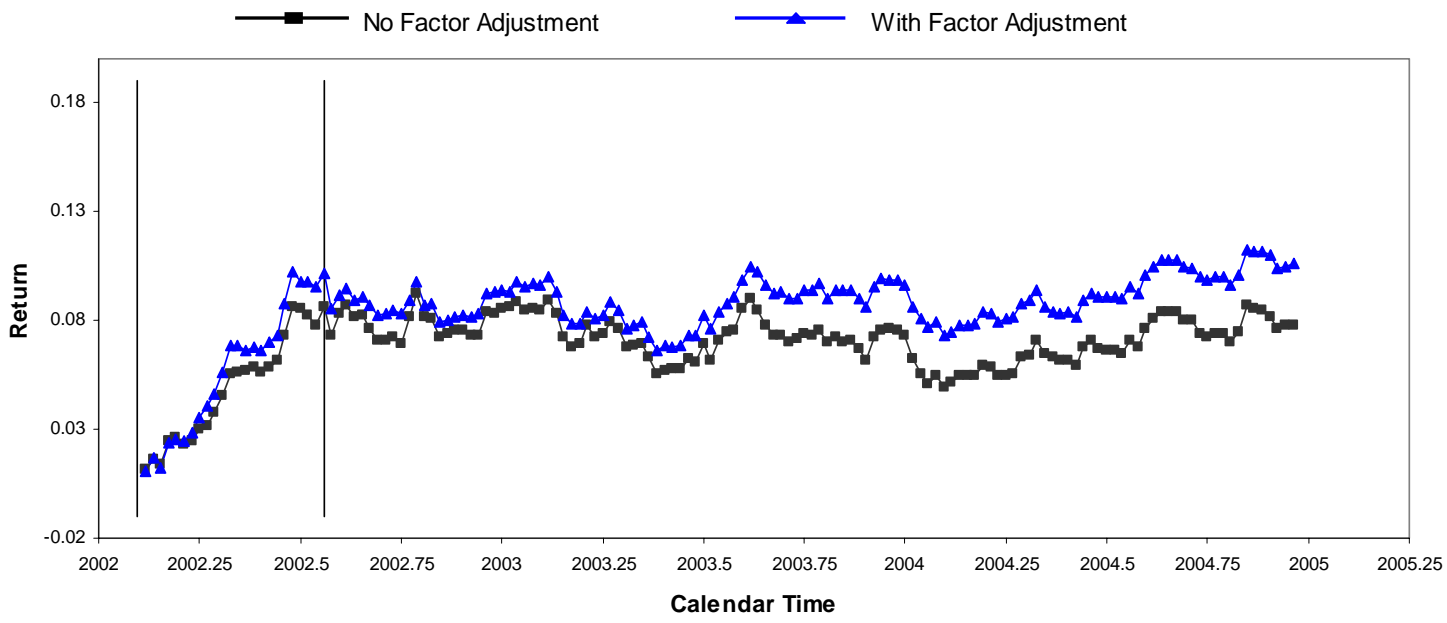

